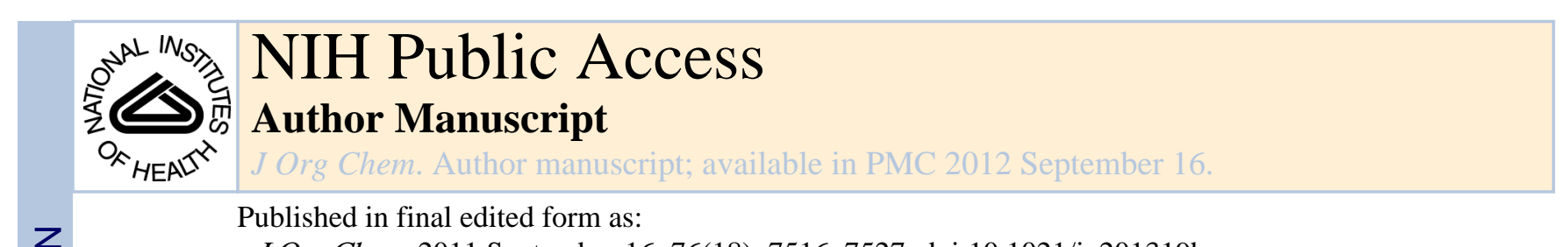

Published in final edited form as:

J Org Chem. 2011 September 16; 76(18): 7516-7527. doi:10.1021/jo201319b.

\title{
Total Synthesis of (-)-4,8,10-Tridesmethyl Telithromycin
}

\author{
Venkata Velvadapu, Tapas Paul, Bharat Wagh, lan Glassford, Charles DeBrosse, and \\ Rodrigo B. Andrade ${ }^{*}$ \\ Temple University, Department of Chemistry, Philadelphia, PA 19122
}

\begin{abstract}

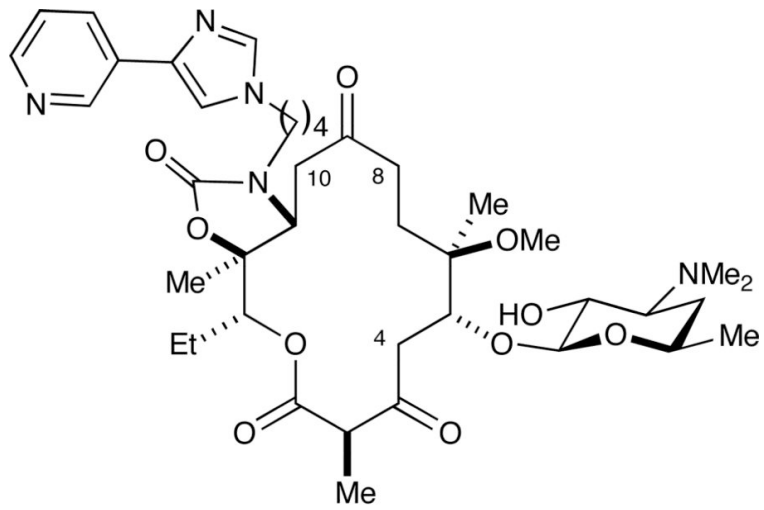

(-)-4,8,10-Tridesmethyl

Telithromycin

Novel sources of antibiotics are required to address the serious problem of antibiotic resistance. Telithromycin (2) is a third-generation macrolide antibiotic prepared from erythromycin (1) and used clinically since 2004. Herein we report the details of our efforts that ultimately led to the total synthesis of (-)-4,8,10-tridesmethyl telithromycin (3) wherein methyl groups have been replaced with hydrogens. The synthesis of desmethyl macrolides has emerged as a novel strategy for preparing bioactive antibiotics.
\end{abstract}

\section{Keywords}

total synthesis; ketolide antibiotics; antibiotic resistance; telithromycin; desmethyl analogues

\section{Introduction}

The incessant rise in antibiotic-resistant bacteria is a serious public health issue. ${ }^{1,2}$ To address this need, we have initiated a structure-based drug design program wherein desmethyl analogues (i.e., $\mathrm{CH}_{3} \rightarrow \mathrm{H}$ ) of the $3^{\text {rd }}$-generation macrolide antibiotic telithromycin (2) are prepared via chemical synthesis (Figure 1). Inspiration for desmethylation came from the Steitz's analysis of x-ray crystal structures of $\mathbf{1}$ and $\mathbf{2}$ bound to the 50S ribosomal

"Corresponding author: tel: +1 215204 7155; fax: +1 215204 9851; randrade@temple.edu.

Supporting Information Available

General experimental procedures and NMR spectra $\left({ }^{1} \mathrm{H}\right.$ and $\left.{ }^{13} \mathrm{C}\right)$ for $\mathbf{2 4 - 2 5}, \mathbf{2 8}, \mathbf{3 0}-\mathbf{3 8}, \mathbf{4 4 - 4 7}, \mathbf{5 3}-\mathbf{5 5}, \mathbf{5 7}$. Crystallographic details of 35. Complete structural assignments ( $2 \mathrm{D}$ NMR analysis) of $\mathbf{6 2}$. This material is available free of charge via the Internet at http://pubs.acs.org. 
subunits of $H$. marismortui, which explains how ribosomal point mutations at critical residues (i.e., A2058G, E. coli numbering) confer antibiotic resistance. ${ }^{3}$

Most modern macrolide antibiotics are semisynthetic analogs of erythromycin A, of which clarithromycin, azithromycin and telithromycin are examples. ${ }^{4}$ As a part of our desmethylation approach to address antibiotic resistance, herein we report the details of our synthetic efforts culminating in the total synthesis of (-)-4,8,10-tridesmethyl telithromycin (3). ${ }^{5}$ We have employed a de novo synthetic strategy to access this simplified ketolide scaffold.

\section{Results and Discussion}

\subsection{Retrosynthesis}

Our approach toward the synthesis of (-)-4,8,10-tridesmethyl telithromycin (3) is shown in Scheme 1 . The retrosynthetic strategy employed was guided by prior art in the field. Specifically, we envisioned the use of a sequential one-pot carbamoylation/intramolecular aza-Michael method developed by Baker and co-workers at Abbott to install the C11-C12 oxazolidinone with pendant butylarene to access 4 from $5 .{ }^{6}$ In fact, this tactic was employed by Hoechst Marion Roussel (HMR) with $\mathbf{6}$ in their synthesis of HMR-3647 (i.e., telithromycin). ${ }^{7}$ Glycosylation of a C5 hydroxyl acceptor derived from $\mathbf{5}$ would be accomplished with known desosamine donor $7 .{ }^{8}$ To prepare macroketolactone $\mathbf{5}$, we utilized two tactics employed in the synthesis of the related ketolide, narbonolide: (1) the intramolecular Nozaki-Hiyama-Kishi (NHK) reaction employed by Sherman and Fecik ${ }^{9}$ and (2) the intramolecular ring-closing metathesis (RCM) strategy employed by Kang and coworkers. ${ }^{10}$ The NHK and RCM substrates could be accessed by an intermolecular Yamaguchi esterification, ${ }^{11}$ which then leads to fragments $\mathbf{8 , 9}$ and 10, the latter of which will be subjected to the Evans aldol reaction to set stereocenters at C2 and C3. ${ }^{12}$ Finally, the Sharpless asymmetric dihydroxylation (AD) reaction ${ }^{13}$ of olefin $\mathbf{1 1}$, which is prepared via a Johnson-Claisen orthoester rearrangement, would establish the requisite configurations and oxidation states at both $\mathrm{C} 5$ and C6.

\subsection{Synthesis}

The preparation of fragments 8 and 9 was accomplished from aldehyde 15, which was synthesized from 12 (Scheme 2). Kinetic resolution of rac-12 via the Sharpless asymmetric epoxidation protocol provided enantioenriched alcohol $\mathbf{1 3}$ in $32 \%$ yield (92\% ee). ${ }^{14}$ Regioselective ring-opening with pivalic acid and $\operatorname{Ti}(\mathrm{O}-i \mathrm{Pr})_{4}$, acetonide formation and treatment with MeLi afforded alcohol 14 (59\% over three steps). ${ }^{15}$ Swern oxidation of $\mathbf{1 4}$ to aldehyde $15^{16}$ proceeded without incident. At this point, $\mathbf{1 5}$ was subjected to the CoreyFuchs alkynylation protocol (59\% yield from 14). ${ }^{17}$ Hydrostannation of the intermediary alkyne with $\mathrm{Bu}_{3} \mathrm{SnH}$ and catalytic AIBN proceeded with excellent stereocontrol to afford an (E)-vinyl stannane, ${ }^{18}$ which was converted to vinyl iodide $\mathbf{1 6}$ with $\mathrm{I}_{2}$ in $80 \%$ over two steps. Removal of the acetonide in $\mathbf{1 6}$ with $1 \mathrm{M} \mathrm{HCl}$ (aq.) furnished fragment 8 (72\% yield). Access to fragment 9 was accomplished by (1) Wittig methylenation of $\mathbf{1 5}$ and (2) removal of the acetonide in $\mathbf{1 7}$ under acidic conditions in 53\% yield from $\mathbf{1 4} .^{16}$

With fragments 8 and $\mathbf{9}$ in hand, attention was turned to the preparation of fragment $\mathbf{1 0}$ (Scheme 1). To this end, commercially available 3-benzyloxy-propanol (18) was oxidized using the Swern protocol (Scheme 3). Addition of 2-propenyl $\mathrm{MgBr}$ and subsequent Johnson-Claisen orthoester rearrangement afforded enoate $\mathbf{1 1}$ in $48 \%$ overall yield. Reduction of the ester and protection of the newly formed alcohol as its tertbutyldimethylsilyl (TBS) ether provided 19 (78\% yield over two steps). ${ }^{19}$ Sharpless dihydroxylation (AD mix- $\beta$ ) established the requisite stereochemistry of the hydroxyls at C5 
and C6 in 91\% yield (er>20:1). ${ }^{13}$ Selective protection of the secondary C5 alcohol with TBSOTf and 2,6-lutidine followed by treatment with $\mathrm{NaH}$ and MeI resulted in the formation of $\mathbf{2 4}$ as opposed to the desired regioisomer $\mathbf{2 3}$ in $70 \%$ over two steps via a 1,4 silyl $O \rightarrow O$ migration (Scheme 3). ${ }^{20}$ This migration came to light when we succeeded in obtaining a single crystal x-ray structure of cyclized product $\mathbf{3 5}$ (see Scheme 5). A survey of the literature revealed this to be a common undesired pathway that attends the generation of a nucleophilic alkoxide bearing a tethered trialkylsilyl ether. ${ }^{21}$ With the undesired regioisomer in hand, we pressed forward.

Hydrogenolysis of benzyl ether $\mathbf{2 4}$ afforded alcohol 25 in $80 \%$ yield (Scheme 4). Swern oxidation of $\mathbf{2 5}$ to aldehyde $\mathbf{2 6}$ was followed by the Evans aldol reaction with propionimide 27, which set the stereochemistry at $\mathrm{C} 2$ and $\mathrm{C} 3$ positions in $78 \%$ yield $(\mathrm{dr}>20: 1)$ over two steps. Protection of the $\mathrm{C} 3$ hydroxyl in $\mathbf{2 8}$ with TBSOTf and removal of the auxiliary with $\mathrm{LiOOH}$ delivered acid $\mathbf{3 0}$ in $85 \%$ yield over two steps. Chemo-selective Yamaguchi esterification of $\mathbf{3 0}$ and diol $\mathbf{8}$ afforded ester $\mathbf{3 1}$ in $74 \%$ yield.

To prepare the intramolecular NHK substrate $\mathbf{3 3}$, the primary TBS ether of $\mathbf{3 1}$ was selectively removed under acidic conditions in $85 \%$ yield (Scheme 5). Oxidation of alcohol 32 with the Dess-Martin Periodinane (DMP) ${ }^{22}$ and $\mathrm{NaHCO}_{3}$ proceeded smoothly to furnish 33 in $80 \%$ yield. The key step was thus effected with by adding excess $\mathrm{CrCl}_{2}$ and catalytic $\mathrm{NiCl}_{2}$ to 33 in degassed DMSO $(0.0025 \mathrm{M})$ at $\mathrm{rt}$ for $16 \mathrm{~h}$, affording a $50 \%$ yield of $\mathbf{3 4}$ as a 1:1 mixture of diastereomeric allylic alcohols at C9. Subsequent oxidation of $\mathbf{3 4}$ with DMP and pyridine furnished macroketolactone $\mathbf{3 5}$, which fortunately was a solid.

Recrystallization of $\mathbf{3 5}$ from $\mathrm{Et}_{2} \mathrm{O}$ by slow evaporation resulted in crystals suitable for $\mathrm{x}$-ray analysis. To our surprise, the groups on C5 and C6 positions in regioisomeric $\mathbf{3 3}$ had been transposed.

To rectify this issue, we revisited the methylation reaction responsible for the attendant transposition. We reasoned that employing a more reactive methylating agent (e.g., Meerwein's salt) would avoid the unwanted $1,4 O \rightarrow O$ silyl migration enabled by reactive metal alkoxide 21 (Scheme 3). In addition, we recruited the TES protecting group to establish an orthogonal set at $\mathrm{C} 3$ and $\mathrm{C} 5$ and offer recourse in the event a regioselective glycosylation was unsuccessful (Scheme 6). To prepare substrate 36, we protected the secondary C5 hydroxyl as a TES ether under standard conditions (90\% yield). Methylation of 36 with $\mathrm{Me}_{3} \mathrm{OBF}_{4}$ (i.e., Meerwein's salt) and Proton Sponge in $\mathrm{CH}_{2} \mathrm{Cl}_{2}$ afforded desired regioisomer 38. ${ }^{23}$ Moreover, subjection to rearrangement conditions (i.e., $\mathrm{NaH}$ and $\mathrm{MeI}$ ) furnished the expected, undesired regioisomer 37.

With correct regioisomer 38 in hand, we reiterated the sequence employed in Schemes 4 and 5. Thus, removal of the benzyl ether in $\mathbf{3 8}$ afforded alcohol $\mathbf{3 9}$ in $85 \%$ yield (Scheme 7). Oxidation of $\mathbf{3 9}$ with the Swern protocol followed by the Evans aldol reaction furnished $\mathbf{4 1}$ in $78 \%$ yield ( $\mathrm{dr}>20: 1)$. Protection of the C3 hydroxyl with TBSOTf and removal of the auxiliary with LiOOH resulted in acid $\mathbf{4 3}$ in $85 \%$ yield over two steps. Yamaguchi esterification of $\mathbf{4 3}$ and $\mathbf{8}$ delivered ester $\mathbf{4 4}$ in $75 \%$ yield. Removal of the primary TBS group with $\mathrm{TBAF} / \mathrm{AcOH}$ (78\% borsm) and subsequent DMP oxidation (78\% yield) set the stage for the intramolecular NHK on $\mathbf{4 6}$. In the event, a 50\% yield of $\mathbf{4 7}$ was obtained. Oxidation of the $\sim 1: 1$ diastereomeric mixture of allylic alcohols at $\mathrm{C} 9$ furnished desired macroketolactone $\mathbf{4 8}$ in $80 \%$ yield.

In parallel, we developed a scalable RCM route inspired by Kang's synthesis of narbonolide (Scheme 8). ${ }^{24}$ To this end, we employed Yamaguchi's method to couple acid $\mathbf{4 3}$ and diol 9 to access ester 49 in $75 \%$ yield. Selective removal of the primary TBS ether with TBAF/ AcOH afforded alcohol $\mathbf{5 0}$ (65\% yield). Oxidation of $\mathbf{5 0}$ with DMP, treatment with vinyl 
$\mathrm{MgBr}$ and subsequent oxidation with DMP furnished RCM substrate $\mathbf{5 1}$ in 60\% over three steps. The RCM reaction proceeded smoothly in $\mathrm{CH}_{2} \mathrm{Cl}_{2}(0.01 \mathrm{M})$ at $\mathrm{rt}$ for $20 \mathrm{~h}$ with $20 \mathrm{~mol}$ $\%$ Grubbs $2^{\text {nd }}$ Generation catalyst to provide 48 in $60 \%$ yield. ${ }^{25}$

With macroketolactone $\mathbf{4 8}$ in hand, attention was directed at the installation of the desosamine moiety onto the C5 hydroxyl. To this end, the C5 TES ether was removed under various conditions (e.g., $p$-TsOH, PPTS, HF). Unfortunately, this was accompanied by ketalization at the $\mathrm{C} 9$ position (Scheme 9) as a consequence of the acidic conditions employed to remove the TES group

Treatment of $\mathbf{4 8}$ with TBAF (i.e., basic conditions) resulted in the removal of both silyl groups, affording triol $\mathbf{5 4}$ in 70\% yield (Scheme 10). Studies by Martin ${ }^{26}$ and Toshima and Tatsuta $^{27}$ both demonstrated the viability of regioselective glycosylations in closely related erythronolide systems. Attempted regioselective glycosylation of $\mathbf{5 4}$ at $\mathrm{C} 5$ in the presence of $\mathrm{C} 3$ with donor 7 under the agency of AgOTf and 2,6-di-t-Bu-4-Me-pyridine (DTBMP) led exclusively to the decomposition of starting material.

Recourse at this point was made to a more conservative strategy. Specifically, we chose to install desosamine with the $\mathrm{C} 3$ position blocked assuming the secondary $\mathrm{C} 5$ hydroxyl would be more reactive than the hindered tertiary $\mathrm{C} 12$ hydroxyl. To test this plan, the $\mathrm{C} 9$ ketone of 48 was first subjected to a Luche reduction to give an inseparable 7:1 mixture of diastereomers that was carried throughout the synthesis (Scheme 11). ${ }^{28}$ Treatment with $p$ $\mathrm{TsOH}$ in methanol selectively removed the C5 TES ether in the presence of the C3 TBS ether to afford triol 55. Regioselective protection of the more reactive allylic $\mathrm{C} 9$ hydroxyl with TESCl and imidazole furnished diol 56. Glycosylation of $\mathbf{5 6}$ with donor 7, AgOTf and DTBMP resulted in the desosamine at the $\mathrm{C} 12$ position, as opposed to the desired $\mathrm{C} 5$. This was confirmed by (1) 2D NMR experiments, particularly an HMBC correlation between the anomeric proton in desosamine with the C12 carbon and (2) removal of C9 TES and oxidation of product with DMP resulted in a triketo species (structure not shown).

We speculate that glycosylation at the more hindered C-12 hydroxyl is due to two factors. First, the C-12 hydroxyl in $\mathbf{5 6}$ is allylic and therefore more nucleophilic (and less sterically demanding) than Tatsuta's C-12 substrate, which was flanked by a 9,11-isopropylidene ketal. ${ }^{27}$ Second, conformational properties of macrolactone acceptor $\mathbf{5 6}$ may render C-5 more sterically shielded. The unexpected glycosylation at the more hindered position necessitated protection at this position as well (Scheme 12). Accordingly, macroketolactone 48 was first reduced under Luche conditions. Silylation of both C9 and C12 hydroxyls with TESOTf and 2,6-lutidine and subsequent treatment with $p$-TsOH selectively afforded $\mathbf{5 8}$ wherein only the tertiary $\mathrm{C} 12$ hydroxyl remained protected (52\% yield over three steps). Regioselective silylation of the allylic $\mathrm{C} 9$ alcohol with TESCl furnished 59. Glycosylation at the $\mathrm{C} 5$ position with donor 7 was accomplished in 50\% yield over two steps. Fluoridemediated cleavage of silyl ethers at C9, C12 with TBAF followed by DMP oxidation at C9 afforded glycosylated macroketolactone $\mathbf{6 2}$ (84\% yield over two steps). The structure of $\mathbf{6 2}$ was rigorously confirmed by 2D NMR experiments (see supporting information).

The endgame for (-)-4,8,10-tridesmethyl telithromycin (3) began with a sequence employed by HMR to prepare C11-C12 oxazolidinones, originally developed by Baker and coworkers at Abbott. ${ }^{6}$ Activation of the $\mathrm{C} 12$ alcohol in $\mathbf{6 2}$ with $\mathrm{NaH}$ and carbonyldiimidazole (CDI) followed by treatment with butylamine $\mathbf{6}^{7}$ effected a tandem carbamoylation/ intramolecular aza-Michael sequence to stereoselectively afford oxazolidinone $\mathbf{6 3}$ in 35\% overall yield. Removal of the C3 TBS ether with tris(dimethylamino)sulfonium difluorotrimethylsilicate (TAS-F) proceeded in $70 \%$ yield. ${ }^{29}$ Alternative fluoride-mediated methods (e.g., TBAF, HF॰pyridine, HF) were all inferior. Corey-Kim oxidation furnished 
the $\mathrm{C} 3$ ketone $4 .{ }^{30}$ Finally, methanolysis removed the methyl carbonate from the $\mathrm{C} 2$ ' position of desosamine to deliver (-)-4,8,10-tridesmethyl telithromycin (3) in $45 \%$ overall yield.

\section{Conclusion}

In conclusion, we have prepared (-)-4,8,10-tridesmethyl telithromycin (3), a desmethyl analogue of FDA-approved ketolide antibiotic telithromycin (2), by total synthesis. Both the intramolecular NHK and RCM reactions were used to prepare the 14-membered ring. Glycosylation using known desosamine donor $\mathbf{7}$ and Baker's sequential one-pot carbamoylation/intramolecular aza-Michael method with amine $\mathbf{6}$ were representative key steps. Ultimately, we were able to prepare a total of $12.1 \mathrm{mg}$ of analogue $\mathbf{3}$ in 42 steps ( 31 steps in the longest linear sequence), which was active against several wild type and resistant bacterial strains. ${ }^{5}$

\section{Experimental section}

$(R)$-5-((R)-3-(benzyloxy)-1-methoxypropyl)-2,2,3,3,5,10,10,11,11-nonamethyl-4,9dioxa-3,10-disiladodecane (24). To a solution of diol $20(2.5 \mathrm{~g}, 18.29 \mathrm{mmol})$ in $\mathrm{CH}_{2} \mathrm{Cl}_{2}$ (30 $\mathrm{mL})$ at $-20^{\circ} \mathrm{C}$ was added 2,6 -lutidine $(2.10 \mathrm{~g}, 19.59 \mathrm{mmol})$ and TBSOTf $(2.07 \mathrm{~g}, 7.83$ $\mathrm{mmol})$. After $2 \mathrm{~h}$, the reaction was quenched by adding sat'd aq. $\mathrm{NaHCO}_{3}(20 \mathrm{~mL})$. The aqueous layer was extracted with $\mathrm{CH}_{2} \mathrm{Cl}_{2}(2 \times 10 \mathrm{~mL})$. The combined organic layers were washed with brine $(20 \mathrm{~mL})$, dried $\left(\mathrm{Na}_{2} \mathrm{SO}_{4}\right)$ and filtered. The solvent was evaporated under reduced pressure, azeotroped with toluene $(20 \mathrm{~mL})$ and dried under high vacuum. The residue was dissolved in THF $(130 \mathrm{~mL})$, MeI $(2.01 \mathrm{~g}, 32.65 \mathrm{mmol})$ was added, and the solution was cooled to $0{ }^{\circ} \mathrm{C}$. Sodium hydride $(0.78 \mathrm{~g}, 32.65 \mathrm{mmol})$ was added slowly in portions. The reaction mixture was warmed to $\mathrm{rt}$ and stirred for $16 \mathrm{~h}$. The reaction mixture was quenched by adding $\mathrm{MeOH}(30 \mathrm{~mL})$ followed by $\mathrm{H}_{2} \mathrm{O}(50 \mathrm{~mL})$ at $0{ }^{\circ} \mathrm{C}$. The reaction mixture was diluted with $\mathrm{Et}_{2} \mathrm{O}(150 \mathrm{~mL})$, and the aqueous layer was extracted with $\mathrm{Et}_{2} \mathrm{O}$ (2 $\times 50 \mathrm{~mL})$. The combined organics were washed with brine $(50 \mathrm{~mL})$, dried $\left(\mathrm{Na}_{2} \mathrm{SO}_{4}\right)$ and filtered. The solvent was concentrated under reduced pressure, and the residue was purified by flash chromatography eluting with EtOAc/hexanes (0.4:1) to afford $2.9 \mathrm{~g}(70 \%)$ of $\mathbf{2 4}$ as colorless oil. $[\alpha]^{23} \mathrm{D}+9.4^{\circ}\left(c 1.8, \mathrm{CH}_{2} \mathrm{Cl}_{2}\right)$; IR (film) 2880, 1475, 1422, 1361, 1055, 733, $696 \mathrm{~cm}^{-1} ;{ }^{1} \mathrm{H}$ NMR $(400 \mathrm{MHz}) \delta$ 7.27-7.17 (m, 5H), $4.45(\mathrm{~d}, J=11.6 \mathrm{~Hz}, 1 \mathrm{H}), 4.41(\mathrm{~d}, J=$ $12.0 \mathrm{~Hz}, 1 \mathrm{H}), 3.53-3.47(\mathrm{~m}, 4 \mathrm{H}), 3.33(\mathrm{~s}, 3 \mathrm{H}), 3.08(\mathrm{dd}, J=10.0,2.2 \mathrm{~Hz}, 1 \mathrm{H}), 1.90-1.87(\mathrm{~m}$, $1 \mathrm{H}), 1.55-1.34(\mathrm{~m}, 5 \mathrm{H}), 1.14(\mathrm{~s}, 3 \mathrm{H}), 0.82(\mathrm{~s}, 9 \mathrm{H}), 0.80(\mathrm{~s}, 9 \mathrm{H}), 0.02(\mathrm{~s}, 6 \mathrm{H}),-0.04(\mathrm{~s}$, $6 \mathrm{H}) ;{ }^{13} \mathrm{C}$ NMR (100 MHz) $\delta 138.6,128.3$ (2), 127.5 (2), 127.4, 84.9, 78.4, 72.8, 67.8, 63.7, 60.7, 35.1, 30.8, 27.0, 26.1 (3C), 26.0 (3C), 24.0, 18.4, 18.3, -1.8, -1.9, -5.3 (2); HRMS (FAB) calc'd for $\mathrm{C}_{28} \mathrm{H}_{54} \mathrm{O}_{4} \mathrm{Si}_{2}+\mathrm{Na}=533.3458$, found 533.3442 .

(3R,4R)-4,7-bis((tert-butyldimethylsilyl)oxy)-3-methoxy-4-methylheptan-1-ol (25). To a solution of ether $24(2.9 \mathrm{~g}, 5.67 \mathrm{mmol})$ in $\mathrm{EtOH}(56 \mathrm{~mL})$ was added $10 \% \mathrm{Pd} / \mathrm{C}(0.6 \mathrm{~g}, 0.56$ mmol) under an atmosphere of $\mathrm{H}_{2}$. The reaction mixture was followed 4-8 h (TLC control). The reaction mixture was filtered through a Celite plug, which had been previously washed with EtOAc. The solvent was concentrated under reduced pressure, and the residue was purified by flash chromatography eluting with EtOAc/hexanes (0.8:1) to afford $1.9 \mathrm{~g} \mathrm{(80 \% )}$ of 25 as a colorless oil. $[\alpha]^{23} \mathrm{D}+6.0^{\circ}\left(c 6.8, \mathrm{CH}_{2} \mathrm{Cl}_{2}\right)$; IR (film) $3306,2953,2928,2885$, $1471,1462,1253,1098,1055,831,811,770 \mathrm{~cm}^{-1} ;{ }^{1} \mathrm{H}$ NMR $(400 \mathrm{MHz}) \delta 3.78-3.72(\mathrm{~m}$, $2 \mathrm{H}), 3.57-3.52(\mathrm{~m}, 2 \mathrm{H}), 3.48(\mathrm{~s}, 3 \mathrm{H}), 3.20(\mathrm{dd}, J=10.0,2.8 \mathrm{~Hz}, 1 \mathrm{H}), 2.40(\mathrm{bs}, 1 \mathrm{H})$, $1.82-1.76(\mathrm{~m}, 1 \mathrm{H}), 1.65-1.39(\mathrm{~m}, 5 \mathrm{H}), 1.21(\mathrm{~s}, 3 \mathrm{H}), 0.87(\mathrm{~m}, 9 \mathrm{H}), 0.84(\mathrm{~s}, 9 \mathrm{H}), 0.95(\mathrm{~m}, 6 \mathrm{H})$, 0.02 (s, 6H); ${ }^{13} \mathrm{C}$ NMR (100 MHz) $\delta$ 86.6, 78.6, 63.6, 61.0, 60.8, 35.4, 33.0, 26.9, 26.0 (3C), 25.9 (3C), 23.9, 18.3, 18.2, $-1.8,-1.9,-5.4$ (2C); HRMS (FAB) calc'd for $\mathrm{C}_{21} \mathrm{H}_{48} \mathrm{O}_{4} \mathrm{Si}_{2}+\mathrm{Na}=443.2989$, found 443.2973. 
(R)-4-benzyl-3-((2R,3S,5R,6R)-6,9-bis((tert-butyldimethylsilyl)oxy)-3-hydroxy-5methoxy-2,6-dimethylnonanoyl)oxazolidin-2-one (28). To a solution of oxalyl chloride $(0.61 \mathrm{~g}, 4.86 \mathrm{mmol})$ in $\mathrm{CH}_{2} \mathrm{Cl}_{2}(30 \mathrm{~mL})$ at $-78{ }^{\circ} \mathrm{C}$ was added DMSO $(0.79 \mathrm{~g}, 10.12 \mathrm{mmol})$ dropwise. After stirring for $10 \mathrm{~min}$, alcohol $25(1.70 \mathrm{~g}, 4.05 \mathrm{mmol})$ in $\mathrm{CH}_{2} \mathrm{Cl}_{2}(10 \mathrm{~mL})$ was added via cannula, and the reaction mixture was stirred at $-78{ }^{\circ} \mathrm{C}$ for $45 \mathrm{~min}$. Triethylamine $(1.02 \mathrm{~g}, 10.12 \mathrm{mmol})$ was added dropwise by cannula, and the reaction mixture was slowly warmed to rt. After $2 \mathrm{~h}$, the reaction was quenched with dropwise addition of $\mathrm{H}_{2} \mathrm{O}(10 \mathrm{~mL})$. The organic layer was separated and washed with brine $(10 \mathrm{~mL})$, dried $\left(\mathrm{Na}_{2} \mathrm{SO}_{4}\right)$ and concentrated under reduced pressure. The crude product was dissolved in $\mathrm{Et}_{2} \mathrm{O}(50 \mathrm{~mL})$, filtered through a plug of silica gel using ether, concentrated and dried under high vacuum. This material was used directly without further purification. To a solution of $(R)-4-$ benzyl-3propionyl-2-oxazolidinone (27) $(0.94 \mathrm{~g}, 4.05 \mathrm{mmol})$ in $\mathrm{CH}_{2} \mathrm{Cl}_{2}(20 \mathrm{~mL})$ was added dibutylborontriflate $\left(5.30 \mathrm{~mL}\right.$ of a $1.0 \mathrm{M}$ solution in $\mathrm{CH}_{2} \mathrm{Cl}_{2}, 5.26 \mathrm{mmol}$ ) and triethylamine $(0.61 \mathrm{~g}, 6.07 \mathrm{mmol})$ dropwise at $0{ }^{\circ} \mathrm{C}$. The solution was cooled to $-78{ }^{\circ} \mathrm{C}$ and to this was added the aldehyde $(1.70 \mathrm{~g}, 4.05 \mathrm{mmol})$ in $\mathrm{CH}_{2} \mathrm{Cl}_{2}(10 \mathrm{~mL})$ at $-78^{\circ} \mathrm{C}$. The resulting solution was stirred for $20 \mathrm{~min}$ at $-78^{\circ} \mathrm{C}$. After warming the solution to $0{ }^{\circ} \mathrm{C}$, the reaction mixture was stirred an additional hour. The reaction was terminated by adding a pH 7 aq. phosphate buffer solution $(0.2 \mathrm{M}$ aq. sodium hydrogen phosphate/ $0.1 \mathrm{M}$ aq. citric acid, $82: 18,8.0 \mathrm{~mL})$ and $\mathrm{MeOH}(24.2 \mathrm{~mL})$. To this cloudy solution was added a solution of $\mathrm{MeOH}$ and $30 \% \mathrm{H}_{2} \mathrm{O}_{2}(2: 1,24.2 \mathrm{~mL})$, and the resulting solution was stirred for $1 \mathrm{~h}$ at $0{ }^{\circ} \mathrm{C}$. The solution was concentrated and extracted with EtOAc $(3 \times 60 \mathrm{~mL})$. The organic layer was washed with sat'd aq. $\mathrm{NaHCO}_{3}(50 \mathrm{~mL})$, brine $(50 \mathrm{~mL})$, dried $\left(\mathrm{Na}_{2} \mathrm{SO}_{4}\right)$ and filtered. The solvent was evaporated under reduced pressure and the residue purified by flash chromatography eluting with EtOAc/hexanes (2:1) to afford $1.50 \mathrm{~g}(78 \%)$ of $\mathbf{2 8}$ as colorless oil. $[\alpha]^{23} \mathrm{D}-39.2^{\circ}\left(c 3.75, \mathrm{CH}_{2} \mathrm{Cl}_{2}\right)$; IR (film) $3500,2953,2885,2856,1781,1696,1382$, $1359,1252,1208,1195,1097,1051,1004,832,771,700 \mathrm{~cm}^{-1} ;{ }^{1} \mathrm{H}$ NMR $(400 \mathrm{MHz}) \delta$ 7.30-7.14 (m, 5H), 4.65-4.60 (m, 1H), 4.17-4.10 (m, 2H), 4.07-4.04 (m, 1H), 3.82-3.79 (m, $2 \mathrm{H}), 3.63(\mathrm{~d}, J=1.2 \mathrm{~Hz}, 1 \mathrm{H}), 3.52(\mathrm{t}, J=5.8 \mathrm{~Hz}, 2 \mathrm{H}), 3.46(\mathrm{~s}, 3 \mathrm{H}), 3.25-3.20(\mathrm{~m}, 2 \mathrm{H}), 2.71$ (dd, $J=13.4,9.4 \mathrm{~Hz}, 1 \mathrm{H}), 1.74-1.34(\mathrm{~m}, 6 \mathrm{H}), 1.22(\mathrm{~d}, J=7.2 \mathrm{~Hz}, 3 \mathrm{H}), 1.19$ (s, 3H), 0.83 (s, 9H), 0.80 (s, 9H), 0.05 (s, 6H), $-0.01(\mathrm{~s}, 6 \mathrm{H}) ;{ }^{13} \mathrm{C}$ NMR $(100 \mathrm{MHz}) \delta 175.8,153.1,135.2$, 129.4 (2C), 128.9 (2C), 127.3, 88.7, 78.7, 71.8, 66.0, 63.6, 60.7, 55.3, 43.0, 37.7, 36.3, 35.1, 34.2, 26.9, 26.0 (3C), 25.9 (3C), 24.1, 18.3, 11.4, -1.8, -1.8, -5.3; HRMS (FAB) calc'd for $\mathrm{C}_{34} \mathrm{H}_{61} \mathrm{NO}_{7} \mathrm{Si}_{2}+\mathrm{Na}=674.3884$, found 674.3868.

(2R,3S,5R,6R)-3,6,9-tris((tert-butyldimethylsilyl)oxy)-5-methoxy-2,6-dimethylnonanoic acid (30). To a stirred solution of aldol $28(1.41 \mathrm{~g}, 2.16 \mathrm{mmol})$ in $\mathrm{CH}_{2} \mathrm{Cl}_{2}(15 \mathrm{~mL})$ at $0{ }^{\circ} \mathrm{C}$ was added 2,6-lutidine $(0.41 \mathrm{~g}, 3.89 \mathrm{mmol})$ and TBSOTf $(0.85 \mathrm{~g}, 3.24 \mathrm{mmol})$. The reaction mixture was stirred for $15 \mathrm{~min}$ at $0{ }^{\circ} \mathrm{C}$ and quenched with sat'd aq. $\mathrm{NaHCO}_{3}(10 \mathrm{~mL})$. The organic layer was separated, washed with brine $(10 \mathrm{~mL})$, dried $\left(\mathrm{Na}_{2} \mathrm{SO}_{4}\right)$ and filtered. The solvent was concentrated under reduced pressure, and the crude product dissolved in THF/ $\mathrm{H}_{2} \mathrm{O}(4: 1,31 \mathrm{~mL})$. To this was added $30 \%$ aq. $\mathrm{H}_{2} \mathrm{O}_{2}(1.14 \mathrm{~mL}, 10.07 \mathrm{mmol})$ and $0.8 \mathrm{M}$ aq. $\mathrm{LiOH}(4.6 \mathrm{~mL}, 3.65 \mathrm{mmol})$ at $0{ }^{\circ} \mathrm{C}$. The reaction was warmed to rt and stirred for $16 \mathrm{~h}$. The reaction was quenched by adding aq. $\mathrm{Na}_{2} \mathrm{SO}_{3}(1.33 \mathrm{M}, 10 \mathrm{~mL})$ and aq. $\mathrm{NH}_{4} \mathrm{Cl}$ solution (10 $\mathrm{mL})$. The reaction mixture was then diluted with EtOAc $(40 \mathrm{~mL})$. The organic layer was separated and the aqueous layer was back-extracted with EtOAc $(2 \times 20 \mathrm{~mL})$. The combined organic layers were washed with brine $(20 \mathrm{~mL})$, dried $\left(\mathrm{Na}_{2} \mathrm{SO}_{4}\right)$ and filtered. The solvent was concentrated under reduced pressure and the residue purified by flash chromatography eluting with EtOAc/hexanes $(0.4 / 1)$ to yield $1.11 \mathrm{~g}(85 \%)$ of $\mathbf{3 0}$ as a colorless oil. $[\alpha]^{23} \mathrm{D}$ $+5.4^{\circ}$ (c 2.5, $\mathrm{CH}_{2} \mathrm{Cl}_{2}$ ); IR (film) 3538, 2953, 2928, 2886, 2856, 1709, 1471, 1462, 1252, $1097,1053,1003,832,803 \mathrm{~cm}^{-1} ;{ }^{1} \mathrm{H}$ NMR $(400 \mathrm{MHz}) \delta 4.35-4.32(\mathrm{~m}, 1 \mathrm{H}), 3.60-3.52(\mathrm{~m}$, $2 \mathrm{H}), 3.50(\mathrm{~s}, 3 \mathrm{H}), 2.98(\mathrm{~d}, J=9.6 \mathrm{~Hz}, 1 \mathrm{H}), 2.69-2.64(\mathrm{~m}, 1 \mathrm{H}), 1.82-1.76(\mathrm{~m}, 1 \mathrm{H}), 1.67-1.40$ (m, 5H), $1.21(\mathrm{~s}, 3 \mathrm{H}), 1.14(\mathrm{~d}, J=7.2 \mathrm{~Hz}, 3 \mathrm{H}), 0.88(\mathrm{~s}, 9 \mathrm{H}), 0.87(\mathrm{~s}, 18 \mathrm{H}), 0.10(\mathrm{~s}, 3 \mathrm{H}), 0.09$ $(\mathrm{s}, 3 \mathrm{H}), 0.07$ (s, 3H), 0.03 (s, 9H); ${ }^{13} \mathrm{C}$ NMR (100 MHz) $\delta 180.1,84.7,78.8,70.7,63.5$, 
60.5, 43.4, 35.8, 35.8, 27.1, 26.1 (3C), 25.9 (3C), 25.8 (3C), 24.1, 18.3, 17.9, 9.5, -1.7, $-1.8,-2.0,-4.2,-5.1,-5.3(2 \mathrm{C})$; HRMS (FAB) calc'd for $\mathrm{C}_{30} \mathrm{H}_{66} \mathrm{O}_{6} \mathrm{Si}_{3}+\mathrm{Na}=629.4065$, found 629.4047 .

$(2 R, 3 S, 5 R, 6 R)-(3 R, 4 S, E)-4$-hydroxy-6-iodo-4-methylhex-5-en-3-yl 3,6,9-tris( $($ tertbutyldimethylsilyl)oxy)-5-methoxy-2,6-dimethylnonanoate (31). To a solution of acid 30 $(0.22 \mathrm{~g}, 0.36 \mathrm{mmol})$ in THF (4 mL) at rt was added $\mathrm{Et}_{3} \mathrm{~N}(0.04 \mathrm{~g}, 0.38 \mathrm{mmol})$ and 2,4,6trichlorobenzoyl chloride $(0.01 \mathrm{~g}, 0.40 \mathrm{mmol})$. The reaction mixture was stirred for $3 \mathrm{~h} \mathrm{at} \mathrm{rt}$, and the solids were filtered and washed with hexanes $(10 \mathrm{~mL})$. The combined filtrates were concentrated under reduced pressure, dried under vacuum, and dissolved in toluene $(5 \mathrm{~mL})$. To this solution was added iododiol $8(0.11 \mathrm{~g}, 0.43 \mathrm{mmol})$ in toluene $(2 \mathrm{~mL})$ and DMAP $(0.06 \mathrm{~g}, 0.49 \mathrm{mmol})$. After being stirred for $16 \mathrm{~h}$ at $\mathrm{rt}$, the reaction mixture was diluted with EtOAc $(20 \mathrm{~mL})$, washed with sat'd aq. $\mathrm{NaHCO}_{3}(10 \mathrm{~mL})$, dried $\left(\mathrm{Na}_{2} \mathrm{SO}_{4}\right)$ and filtered. The solvent was evaporated under reduced pressure and the residue purified by flash chromatography eluting with EtOAc/hexanes (0.4/1) to afford $0.24 \mathrm{~g}(74 \%)$ of 31 as a colorless oil. $[\alpha]^{23} \mathrm{D}+11.2^{\circ}$ (c 1.2, $\mathrm{CH}_{2} \mathrm{Cl}_{2}$ ); IR (film) 3445, 2951, 2936, 2909, 2877, 2857, $1729,1461,1251,1192,1095,1004,950,836,775 \mathrm{~cm}^{-1} ;{ }^{1} \mathrm{H}$ NMR $(400 \mathrm{MHz}) \delta 6.68(\mathrm{~d}, J$ $=14.6 \mathrm{~Hz}, 1 \mathrm{H}), 6.43(\mathrm{~d}, J=14.6,1 \mathrm{H}), 4.81(\mathrm{dd}, J=10.4,2.8 \mathrm{~Hz}, 1 \mathrm{H}), 4.14-4.10(\mathrm{~m}, 1 \mathrm{H})$, $3.58-3.50(\mathrm{~m}, 2 \mathrm{H}), 3.50(\mathrm{~s}, 3 \mathrm{H}), 3.25(\mathrm{dd}, J=9.6,3.2 \mathrm{~Hz}, 1 \mathrm{H}), 3.18(\mathrm{bs}, 1 \mathrm{H}), 2.74-2.61(\mathrm{~m}$, $1 \mathrm{H}), 1.68-1.35(\mathrm{~m}, 8 \mathrm{H}), 1.25(\mathrm{~s}, 3 \mathrm{H}), 1.21(\mathrm{~d}, J=4.8 \mathrm{~Hz}, 3 \mathrm{H}), 1.17(\mathrm{~s}, 3 \mathrm{H}), 0.90(\mathrm{~s}, 9 \mathrm{H})$, 0.89-0.86 (m, 21H), $0.11(\mathrm{~s}, 6 \mathrm{H}), 0.07(\mathrm{~s}, 3 \mathrm{H}), 0.06(\mathrm{~s}, 3 \mathrm{H}), 0.02(\mathrm{~s}, 6 \mathrm{H}) ;{ }^{13} \mathrm{C}$ NMR $(100$ $\mathrm{MHz}) \delta 175.8,148.0,83.9,80.2,79.3,77.7,71.2,63.4,60.7,44.3,36.5,35.2,26.7,26.2$ (3C), 26.1, 25.9 (6C), 24.8, 23.5, 23.2, 18.4, 18.3, 18.0, 14.4, 10.7, -1.6, -1.7, -3.8, -4.5, -5.4 (2C); HRMS (FAB) calc'd for $\mathrm{C}_{37} \mathrm{H}_{77} \mathrm{IO}_{7} \mathrm{Si}_{3}+\mathrm{Na}=867.3920$, found 867.3934.

$(2 R, 3 S, 5 R, 6 R)-(3 R, 4 S, E)-4-h y d r o x y-6$-iodo-4-methylhex-5-en-3-yl 3,6-bis( $($ tertbutyldimethylsilyl)oxy)-9-hydroxy-5-methoxy-2,6-dimethylnonanoate (32). To a solution of alcohol $31(0.27 \mathrm{~g}, 0.32 \mathrm{mmol})$ in $\mathrm{MeOH}(7 \mathrm{~mL})$ was added CSA $(0.015 \mathrm{~g}, 0.065 \mathrm{mmol})$ at 0 ${ }^{\circ} \mathrm{C}$. After stirring for $1 \mathrm{~h}$, the reaction was quenched with $\mathrm{NaHCO}_{3}(0.040 \mathrm{~g})$. The mixture was concentrated under reduced pressure, and the residue was purified by flash chromatography eluting with EtOAc/hexanes (1/5) to afford $0.20 \mathrm{~g}(85 \%)$ of 32 as a colorless oil. [ $\alpha]^{23} \mathrm{D}+14.5^{\circ}$ ( $c 0.9, \mathrm{CH}_{2} \mathrm{Cl}_{2}$ ); IR (film) 3458, 2952, 2936, 2908, 2877, 1724, $1461,1251,1194,1094,1045,1005,836,775,735 \mathrm{~cm}^{-1} ;{ }^{1} \mathrm{H}$ NMR $(400 \mathrm{MHz}) \delta 6.67(\mathrm{~d}, J$ $=11.6 \mathrm{~Hz}, 1 \mathrm{H}), 6.42(\mathrm{~d}, J=11.6,1 \mathrm{H}), 4.80(\mathrm{dd}, J=8.4,2.0 \mathrm{~Hz}, 1 \mathrm{H}), 4.80(\mathrm{dt}, J=5.6,2.0$ $\mathrm{Hz}, 1 \mathrm{H}), 3.59(\mathrm{t}, J=4.4 \mathrm{~Hz}, 2 \mathrm{H}), 3.47(\mathrm{~s}, 3 \mathrm{H}), 3.32-3.27(\mathrm{~m}, 2 \mathrm{H}), 2.74-2.70(\mathrm{~m}, 1 \mathrm{H})$, $1.75-1.40(\mathrm{~m}, 8 \mathrm{H}), 1.24(\mathrm{~s}, 3 \mathrm{H}), 1.21(\mathrm{~d}, J=4.8 \mathrm{~Hz}, 3 \mathrm{H}), 1.21(\mathrm{~s}, 3 \mathrm{H}), 0.90(\mathrm{~s}, 9 \mathrm{H})$, 0.88-0.85 (m, 12H), $0.11(\mathrm{~s}, 3 \mathrm{H}), 0.10(\mathrm{~s}, 3 \mathrm{H}), 0.08(\mathrm{~s}, 3 \mathrm{H}), 0.06(\mathrm{~s}, 3 \mathrm{H}) ;{ }^{13} \mathrm{C}$ NMR (100 $\mathrm{MHz}) \delta 175.8,147.8,84.3,80.2,78.9,77.7,77.4,77.3,63.3,60.4,44.6,35.8,34.9,29.6$, 26.2 (3C), 25.9 (3C), 24.5, 24.1, 23.2, 18.4, 18.0, 15.0, 10.6, -1.6, -1.7, -3.9, -4.5; HRMS (FAB) calc'd for $\mathrm{C}_{31} \mathrm{H}_{63} \mathrm{IO}_{7} \mathrm{Si}_{2}+\mathrm{Na}=753.3055$, found 753.3053 .

$(2 R, 3 S, 5 R, 6 R)-(3 R, 4 S, E)-4$-hydroxy-6-iodo-4-methylhex-5-en-3-yl 3,6-bis( $($ tertbutyldimethylsilyl)oxy)-5-methoxy-2,6-dimethyl-9-oxononanoate (33). Dess-Martin periodinane $(0.53 \mathrm{~g}, 0.31 \mathrm{mmol})$ and $\mathrm{NaHCO}_{3}(0.13 \mathrm{~g}, 1.57 \mathrm{mmol})$ were suspended in $\mathrm{CH}_{2} \mathrm{Cl}_{2}(3 \mathrm{~mL})$. Alcohol $32(0.23 \mathrm{~g}, 0.31 \mathrm{mmol})$ in $\mathrm{CH}_{2} \mathrm{Cl}_{2}(3 \mathrm{~mL})$ was added dropwise via cannula into the reaction mixture. After $1 \mathrm{~h}$ at $\mathrm{rt}$, the reaction mixture was added to a mixture of sat'd aq. $\mathrm{NaHCO}_{3}(5 \mathrm{~mL})$, sat'd aq. $\mathrm{Na}_{2} \mathrm{SO}_{3}(5 \mathrm{~mL})$ and $\mathrm{H}_{2} \mathrm{O}(10 \mathrm{~mL})$. The mixture was extracted with $\mathrm{Et}_{2} \mathrm{O}(2 \times 20 \mathrm{~mL})$. The combined organic layers were washed with brine $(10 \mathrm{~mL})$, dried $\left(\mathrm{Na}_{2} \mathrm{SO}_{4}\right)$ and filtered. The solvent was concentrated under reduced pressure, and the residue was purified by flash chromatography eluting with EtOAc/ hexanes $(0.4 / 1)$ to afford $0.18 \mathrm{~g}(80 \%)$ of 33 as a foam. $[\alpha]^{23} \mathrm{D}+14.9^{\circ}\left(c 0.75, \mathrm{CH}_{2} \mathrm{Cl}_{2}\right)$; IR (film) 2962, 2886, 2853, 1736, 1695, 1461, 1401, 1250, 1190, 1094, $1050 \mathrm{~cm}^{-1}$; ${ }^{1} \mathrm{H}$ NMR $(400 \mathrm{MHz}) \delta 9.8(\mathrm{~s}, 1 \mathrm{H}), 6.67(\mathrm{~d}, J=14.4 \mathrm{~Hz}, 1 \mathrm{H}), 6.43$ (d, $J=14.4 \mathrm{~Hz}, 1 \mathrm{H}), 4.81$ (dd, $J=$ 
10.4, $2.8 \mathrm{~Hz}, 1 \mathrm{H}), 4.11(\mathrm{dt}, J=6.8,3.2 \mathrm{~Hz}, 1 \mathrm{H}), 3.47(\mathrm{~s}, 3 \mathrm{H}), 3.21(\mathrm{~d}, J=9.6 \mathrm{~Hz}, 2.4,1 \mathrm{H})$, $3.11(\mathrm{bs}, 1 \mathrm{H}), 1.85-1.50(\mathrm{~m}, 8 \mathrm{H}), 1.25(\mathrm{~s}, 3 \mathrm{H}), 1.21(\mathrm{~d}, J=7.2 \mathrm{~Hz}, 3 \mathrm{H}), 1.21(\mathrm{~s}, 3 \mathrm{H}), 0.90$ (s, 9H), 0.89-0.85 (m, 12H), $0.12(\mathrm{~s}, 3 \mathrm{H}), 0.11(\mathrm{~s}, 3 \mathrm{H}), 0.08(\mathrm{~s}, 3 \mathrm{H}), 0.04(\mathrm{~s}, 3 \mathrm{H}) ;{ }^{13} \mathrm{C} \mathrm{NMR}$ (100 MHz) $\delta 202.1,175.7,148.0,84.1,80.2,78.4,77.7,71.1,60.7,44.5,38.7,35.2,31.4$, 26.1 (3C), 25.9 (3C), 24.6, 23.5, 23.1, 18.4, 18.0, 14.6, 10.7, -1.6, -1.8, -3.9, -4.6; HRMS (FAB) calc'd for $\mathrm{C}_{31} \mathrm{H}_{61} \mathrm{IO}_{7} \mathrm{Si}_{2}+\mathrm{Na}=751.2898$, found 751.2892.

(3R,4S,6R,7R,13S,14R,E)-4,7-bis((tert-butyldimethylsilyl)oxy)-14-ethyl-10,13-dihydroxy-6methoxy-3,7,13-trimethyloxacyclotetradec-11-en-2-one (34). To a solution of aldehyde 33 $(0.20 \mathrm{~g}, 0.27 \mathrm{mmol})$ in DMSO $(125 \mathrm{~mL})$ at $\mathrm{rt}$ was added $\mathrm{CrCl}_{2}(0.33 \mathrm{~g}, 2.75 \mathrm{mmol})$ and $\mathrm{NiCl}_{2}(0.004 \mathrm{mg}, 0.027 \mathrm{mmol})$. The reaction was stirred for $16 \mathrm{~h}$ and quenched by the addition of $\mathrm{H}_{2} \mathrm{O}(60 \mathrm{~mL})$. The mixture was diluted with EtOAc $(500 \mathrm{~mL})$, and the layers were separated. The organic layer was washed with $\mathrm{H}_{2} \mathrm{O}(3 \times 50 \mathrm{~mL})$. The combined aqueous layers were back-extracted with EtOAc $(3 \times 200 \mathrm{~mL})$. The combined organic layers were washed with brine $(200 \mathrm{~mL})$, dried $\left(\mathrm{Na}_{2} \mathrm{SO}_{4}\right)$ and filtered. The solvent was concentrated under reduced pressure, and the residue was purified by flash chromatography eluting with EtOAc/hexanes (1/2) to afford $0.06 \mathrm{~g}(\mathrm{dr}=1: 1$ at C9) (50\%) of $\mathbf{3 4}$ as a foam. IR (film) 3465, 2953, 2909, 1731, 1461, 1251, 1095, 1252, 1118, 1093, $1067 \mathrm{~cm}^{-1}$; ${ }^{1} \mathrm{H}$ NMR $(400 \mathrm{MHz}) \delta 6.85(\mathrm{~d}, J=16.4 \mathrm{~Hz}, 1 \mathrm{H}), 6.19(\mathrm{~d}, J=16.4 \mathrm{~Hz}, 1 \mathrm{H}), 4.83(\mathrm{dd}, J=10.8,1.2 \mathrm{~Hz}$, $1 \mathrm{H}), 4.33(\mathrm{t}, J=8.4 \mathrm{~Hz}, 1 \mathrm{H}), 3.76(\mathrm{dd}, J=9.6,3.2 \mathrm{~Hz}, 1 \mathrm{H}), 3.23(\mathrm{dt}, J=12.8,3.5 \mathrm{~Hz}, 1 \mathrm{H})$, $3.12(\mathrm{~s}, 3 \mathrm{H}), 2.83$ (bs, 1H), 2.46-2.38 (m, 1H), 1.99-1.90 (m, 2H), 1.81-1.52 (m, 5H), 1.33 $(\mathrm{s}, 3 \mathrm{H}), 1.19(\mathrm{~d}, J=8.0 \mathrm{~Hz}, 3 \mathrm{H}), 1.18(\mathrm{~s}, 3 \mathrm{H}), 0.94(\mathrm{t}, J=8.2 \mathrm{~Hz}, 9 \mathrm{H}), 0.89(\mathrm{~s}, 9 \mathrm{H}), 0.86(\mathrm{t}$, $J=7.2 \mathrm{~Hz}, 3 \mathrm{H}), 0.60(\mathrm{q}, J=7.8 \mathrm{~Hz}, 6 \mathrm{H}), 0.13(\mathrm{~s}, 3 \mathrm{H}), 0.04(\mathrm{~s}, 3 \mathrm{H}) ;{ }^{13} \mathrm{C} \mathrm{NMR}(100 \mathrm{MHz}) \delta$ 204.1, 175.7, 151.8, 127.7, 80.1, 78.9, 74.1, 73.2, 71.2, 49.0, 48.3, 44.7, 34.6, 31.1, 26.2, 21.9, 21.0, 19.7, 18.4, 16.1, 10.3, 6.7, 5.1, -3.0, -4.8; HRMS (FAB) calc'd for $\mathrm{C}_{31} \mathrm{H}_{62} \mathrm{O}_{7} \mathrm{Si}_{2}+\mathrm{Na}=625.3932$, found 625.3925

(3R,4S,6R,7R,13S,14R,E)-4,7-bis((tert-butyldimethylsilyl)oxy)-14-ethyl-13-hydroxy-6methoxy-3,7,13-trimethyloxacyclotetradec-11-ene-2,10-dione (35). Dess-Martin periodinane $(0.07 \mathrm{~g}, 0.15 \mathrm{mmol})$ was added to alcohol $34(0.03 \mathrm{~g}, 0.05 \mathrm{mmol})$ in $\mathrm{CH}_{2} \mathrm{Cl}_{2}(5 \mathrm{~mL})$ and pyridine $(0.15 \mathrm{~mL})$. After $1 \mathrm{~h}$ at $\mathrm{rt}$, the reaction mixture was added to a mixture of sat' $\mathrm{d}$ aq. $\mathrm{NaHCO}_{3}(5 \mathrm{~mL})$, sat'd aq. $\mathrm{Na}_{2} \mathrm{SO}_{3}(5 \mathrm{~mL})$ and $\mathrm{H}_{2} \mathrm{O}(10 \mathrm{~mL})$. The mixture was extracted with $\mathrm{Et}_{2} \mathrm{O}(2 \times 20 \mathrm{~mL})$. The combined organic layers were washed with brine $(10 \mathrm{~mL})$, dried $\left(\mathrm{Na}_{2} \mathrm{SO}_{4}\right)$ and filtered. The solvent was concentrated under reduced pressure and the residue was purified by flash chromatography eluting with EtOAc/hexanes $(1.2 / 1)$ to afford $0.024 \mathrm{~g}$ $(82 \%)$ of 35 as a white solid $\left(\mathrm{mp}=192-195^{\circ} \mathrm{C}\right) ;[\alpha]^{23} \mathrm{D}+6.7^{\circ}\left(c 2.7, \mathrm{CH}_{2} \mathrm{Cl}_{2}\right)$; IR (film) 3443, 2956, 2930, 2893, 2883, 2857, 1733, 1658, 1461, 1262, 1126, 1095, 1066, 1053, 1001, $835 \mathrm{~cm}^{-1}$; ${ }^{1} \mathrm{H}$ NMR $(400 \mathrm{MHz}) \delta 7.08(\mathrm{~d}, J=16.4 \mathrm{~Hz}, 1 \mathrm{H}), 6.14(\mathrm{~d}, J=16.4 \mathrm{~Hz}, 1 \mathrm{H})$, $4.77(\mathrm{dd}, J=10.0,2.8 \mathrm{~Hz}, 1 \mathrm{H}), 4.05(\mathrm{dd}, J=10.0,6.8 \mathrm{~Hz}, 1 \mathrm{H}), 3.46(\mathrm{~s}, 3 \mathrm{H}), 3.40-3.31$ (m, 2H), 3.02-2.95 (m, 1H), $2.52(\mathrm{bs}, 1 \mathrm{H}), 2.09-1.52(\mathrm{~m}, 10 \mathrm{H}), 1.34(\mathrm{~s}, 3 \mathrm{H}), 1.30(\mathrm{~s}, 3 \mathrm{H}), 1.25$ $(\mathrm{d}, J=6.8 \mathrm{~Hz}, 3 \mathrm{H}), 0.95-0.89(\mathrm{~m}, 12 \mathrm{H}), 0.80(\mathrm{~s}, 3 \mathrm{H}), 0.07(\mathrm{~s}, 3 \mathrm{H}), 0.07(\mathrm{~m}, 6 \mathrm{H}), 0.05$ (s, $3 \mathrm{H}) ;{ }^{13} \mathrm{C}$ NMR $(100 \mathrm{MHz}) \delta 203.7,176.2,152.5,127.5,86.6,77.3,76.6,73.7,71.7,59.8$, 45.4, 44.7, 34.8, 33.7, 32.7, 26.0 (6C), 25.5, 22.4, 21.5, 18.1, 17.4, 10.6, -1.7, -1.8, -3.9, -4.6; HRMS (FAB) calc'd for $\mathrm{C}_{31} \mathrm{H}_{60} \mathrm{O}_{7} \mathrm{Si}_{2}+\mathrm{Na}=623.3775$ found 623.3736.

(5R,6R)-5-(2-(benzyloxy)ethyl)-3,3-diethyl-6,11,11,12,12-pentamethyl-4,10-dioxa-3,11disilatridecan-6-ol (36). To a solution of diol $20(1.0 \mathrm{~g}, 2.61 \mathrm{mmol})$ in DMF $(26 \mathrm{~mL})$ at $0{ }^{\circ} \mathrm{C}$ was added imidazole $(0.25 \mathrm{~g}, 3.65 \mathrm{mmol})$ and $\mathrm{TESCl}(0.47 \mathrm{~g}, 3.13 \mathrm{mmol})$. The reaction mixture was warmed to rt. After $1.5 \mathrm{~h}$, the reaction was quenched by with $\mathrm{H}_{2} \mathrm{O}(40 \mathrm{~mL})$. The aqueous layer was extracted with ether $(4 \times 50 \mathrm{~mL})$. The combined organic layers were washed with $\mathrm{H}_{2} \mathrm{O}(50 \mathrm{~mL})$ brine $(50 \mathrm{~mL})$, dried $\left(\mathrm{Na}_{2} \mathrm{SO}_{4}\right)$ and filtered. The solvent was concentrated under reduced pressure, and the residue was purified by flash chromatography eluting with EtOAc/hexanes (1/5) to afford $1.16 \mathrm{~g}(90 \%)$ of $\mathbf{3 6}$ as a colorless oil. $[\alpha]^{23} \mathrm{D}$ 
$+7.7^{\circ}$ (c 8.3, $\mathrm{CH}_{2} \mathrm{Cl}_{2}$ ); IR (film) 3443, 2956, 2930, 2893, 2883, 2857, 1733, 1658, 1461, 1262, 1126, 1095, 1066, 1053, 1001, $835 \mathrm{~cm}^{-1}$; ${ }^{1} \mathrm{H}$ NMR $(400 \mathrm{MHz}) \delta 7.29-7.18(\mathrm{~m}, 5 \mathrm{H})$, $4.43(\mathrm{~s}, 2 \mathrm{H}), 3.61(\mathrm{dd}, J=7.2,3.6 \mathrm{~Hz}, 1 \mathrm{H}), 3.54(\mathrm{t}, J=6.4 \mathrm{~Hz}, 2 \mathrm{H}), 3.50-3.47(\mathrm{~m}, 1 \mathrm{H})$, $2.47(\mathrm{~s}, 1 \mathrm{H}), 1.88-1.80(\mathrm{~m}, 1 \mathrm{H}), 1.65-1.36(\mathrm{~m}, 5 \mathrm{H}), 1.02(\mathrm{~s}, 3 \mathrm{H}), 0.88(\mathrm{t}, J=6.4 \mathrm{~Hz}, 9 \mathrm{H}), 0.82$ $(\mathrm{s}, 9 \mathrm{H}), 0.55(\mathrm{q}, J=7.6 \mathrm{~Hz}, 6 \mathrm{H}),-0.02(\mathrm{~s}, 6 \mathrm{H}) ;{ }^{13} \mathrm{C}$ NMR $(100 \mathrm{MHz}) \delta 138.3,128.3(2)$, 127.6 (2), 127.5, 76.0, 74.1, 72.9, 67.3, 63.8, 34.9, 33.1, 26.8, 25.9 (3C), 21.8, 18.2, 6.9 (3C), $5.2(3 \mathrm{C}),-5.3(2 \mathrm{C})$; HRMS (FAB) calc'd for $\mathrm{C}_{27} \mathrm{H}_{52} \mathrm{O}_{4} \mathrm{Si}_{2}+\mathrm{Na}=519.3302$ found 519.3286 .

$(R)-8$-((R)-3-(benzyloxy)-1-methoxypropyl)-10,10-diethyl-2,2,3,3,8-pentamethyl-4,9dioxa-3,10-disiladodecane (37). To a solution of $\mathbf{3 6}(0.50 \mathrm{~g}, 1.00 \mathrm{mmol})$ in THF (10 mL) was added MeI $(2.01 \mathrm{~g}, 32.65 \mathrm{mmol})$, and the reaction mixture was cooled to $0{ }^{\circ} \mathrm{C}$. Sodium hydride $(0.78 \mathrm{~g}, 32.65 \mathrm{mmol})$ was then added in small portions. The reaction mixture was allowed to warm to $\mathrm{rt}$ and stirred for $16 \mathrm{~h}$. The reaction mixture was quenched by adding $\mathrm{MeOH}(3 \mathrm{~mL})$ followed by $\mathrm{H}_{2} \mathrm{O}(5 \mathrm{~mL})$ at $0{ }^{\circ} \mathrm{C}$. The reaction mixture was diluted with $\mathrm{Et}_{2} \mathrm{O}$ $(15 \mathrm{~mL})$, and the aqueous layer was back-extracted with $\mathrm{Et}_{2} \mathrm{O}(2 \times 5 \mathrm{~mL})$. The combined organic layers were washed with brine $(5 \mathrm{~mL})$, dried $\left(\mathrm{Na}_{2} \mathrm{SO}_{4}\right)$ and filtered. The solvent was concentrated under reduced pressure, and the residue was purified by flash chromatography eluting with EtOAc/hexanes $(0.4: 1)$ to afford $0.4 \mathrm{~g}(78 \%)$ of 37 as a colorless oil. $[\alpha]^{23} \mathrm{D}$ $+8.4^{\circ}$ (c 3.8, $\mathrm{CH}_{2} \mathrm{Cl}_{2}$ ); IR (film) 2880, 1475, 1422, 1361, 1055, 733, $696 \mathrm{~cm}^{-1} ;{ }^{1} \mathrm{H} \mathrm{NMR}$ $(400 \mathrm{MHz}) \delta 7.35-7.26(\mathrm{~m}, 5 \mathrm{H}), 4.54(\mathrm{~d}, J=12.0 \mathrm{~Hz}, 1 \mathrm{H}), 4.49(\mathrm{~d}, J=12.0 \mathrm{~Hz}, 1 \mathrm{H})$, $3.61-3.55(\mathrm{~m}, 4 \mathrm{H}), 3.42(\mathrm{~s}, 3 \mathrm{H}), 3.17(\mathrm{dd}, J=10.4,2.4 \mathrm{~Hz}, 1 \mathrm{H}), 1.93-1.89(\mathrm{~m}, 1 \mathrm{H})$, $1.65-1.39(\mathrm{~m}, 5 \mathrm{H}), 1.20(\mathrm{~s}, 3 \mathrm{H}), 0.95(\mathrm{t}, J=8 \mathrm{~Hz}, 9 \mathrm{H}), 0.89(\mathrm{~s}, 9 \mathrm{H}), 0.59(\mathrm{q}, J=8 \mathrm{~Hz}, 6 \mathrm{H})$, 0.04 (s, 6H); ${ }^{13} \mathrm{C}$ NMR (100 MHz) $\delta 138.6,128.3$ (2C), $127.6(2 \mathrm{C}), 127.4,84.6,78.2,72.8$, $67.8,63.7,60.8,35.4,30.8,27.0,26.0$ (3C), 24.2, 18.3, $7.2(3 \mathrm{C}), 6.9(3 \mathrm{C}),-5.3(2 \mathrm{C})$; HRMS (FAB) calc'd for $\mathrm{C}_{28} \mathrm{H}_{54} \mathrm{O}_{4} \mathrm{Si}_{2}+\mathrm{Na}=533.3458$, found 533.3455 .

(8R,9R)-9-(2-(benzyloxy)ethyl)-11,11-diethyl-8-methoxy-2,2,3,3,8-pentamethyl-4,10dioxa-3,11-disilatridecane (38). To a solution of $\mathbf{3 6}(9.08 \mathrm{~g}, 18.29 \mathrm{mmol})$ in $\mathrm{CH}_{2} \mathrm{Cl}_{2}(90$ $\mathrm{mL})$ at $0{ }^{\circ} \mathrm{C}$ was added Proton Sponge $(11.74 \mathrm{~g}, 54.87 \mathrm{mmol})$ and $\mathrm{Me}_{3} \mathrm{OBF}_{4}(8.11 \mathrm{~g}, 54.87$ $\mathrm{mmol})$. The reaction mixture was warmed to $\mathrm{rt}$ and stirred for $16 \mathrm{~h}$. The reaction mixture was concentrated and quenched with sat'd aq. $\mathrm{NH}_{4} \mathrm{Cl}(50 \mathrm{~mL})$. The reaction mixture was diluted with $\mathrm{Et}_{2} \mathrm{O}(100 \mathrm{~mL})$, and the aqueous layer was back-extracted with $\mathrm{Et}_{2} \mathrm{O}(2 \times 50$ $\mathrm{mL})$. The combined organic layers were washed with $1 \mathrm{~N}$ aq. $\mathrm{HCl}$ solution $(60 \mathrm{~mL})$, sat'd aq. $\mathrm{NaHCO}_{3}(80 \mathrm{~mL}), \mathrm{H}_{2} \mathrm{O}(80 \mathrm{~mL})$, brine $(50 \mathrm{~mL})$, dried $\left(\mathrm{Na}_{2} \mathrm{SO}_{4}\right)$ and filtered. The solvent was concentrated under reduced pressure, and the residue was purified by flash chromatography eluting with EtOAc/hexanes (1/25) to afford $7.4 \mathrm{~g}(80 \%)$ of $\mathbf{3 8}$ as an oil. $[\alpha]^{23}{ }_{\mathrm{D}}=+11.5^{\circ}\left(\mathrm{c} 2.6, \mathrm{CH}_{2} \mathrm{Cl}_{2}\right.$ ); IR (film) 1255, 1361, 1471, 2857, 2953, 3398, 1096, 899, 733, $696 \mathrm{~cm}^{-1}$; ${ }^{1} \mathrm{H}$ NMR (400 MHz) $\delta 7.27-7.20(\mathrm{~m}, 5 \mathrm{H}), 4.45(\mathrm{~d}, J=12.0 \mathrm{~Hz}, 1 \mathrm{H}), 4.41$ (d, $J=12.0 \mathrm{~Hz}, 1 \mathrm{H}), 3.74(\mathrm{dd}, J=9.8,2.2 \mathrm{~Hz}, 2 \mathrm{H}), 3.54-3.48(\mathrm{~m}, 4 \mathrm{H}), 3.07(\mathrm{~s}, 3 \mathrm{H}), 1.84-1.76$ $(\mathrm{m}, 1 \mathrm{H}), 1.60-1.28(\mathrm{~m}, 4 \mathrm{H}), 0.98(\mathrm{~s}, 3 \mathrm{H}), 0.88-0.84(\mathrm{~m}, 9 \mathrm{H}), 0.83(\mathrm{~s}, 9 \mathrm{H}), 0.55-0.49(\mathrm{~m}$, $6 \mathrm{H}),-0.02(\mathrm{~s}, 6 \mathrm{H}) ;{ }^{13} \mathrm{C}$ NMR $(100 \mathrm{MHz}) \delta 138.6,128.3(2 \mathrm{C}), 127.6(2 \mathrm{C}), 127.4,78.8,73.7$, 72.9, 67.9, 63.5, 48.7, 32.7, 29.9, 26.0, 25.9 (3C), 18.2, 18.0, 7.1 (3C), 5.3 (3C), -5.3 (2C); HRMS (FAB) calc'd for $\mathrm{C}_{28} \mathrm{H}_{54} \mathrm{O}_{4} \mathrm{Si}_{2}+\mathrm{Na}=533.3458$, found 533.3445.

$(2 R, 3 S, 5 R, 6 R)-(3 R, 4 S, E)-4-h y d r o x y-6-i o d o-4-m e t h y l h e x-5-e n-3-y l ~ 3,9-b i s((t e r t-$

butyldimethylsilyl)oxy)-6-methoxy-2,6-dimethyl-5-((triethylsilyl)oxy)nonanoate (44). To a solution of acid $43(0.60 \mathrm{~g}, 0.98 \mathrm{mmol})$ in THF $(10 \mathrm{~mL})$ at rt were added $\mathrm{Et}_{3} \mathrm{~N}(0.1 \mathrm{~g}, 1.03$ $\mathrm{mmol})$ and 2,4,6-trichlorobenzoyl chloride $(0.26 \mathrm{~g}, 1.08 \mathrm{mmol})$. The reaction mixture was stirred for $3 \mathrm{~h}$ at $\mathrm{rt}$, and the solids were filtered and washed with hexanes $(20 \mathrm{~mL})$. The combined filtrates were concentrated under reduced pressure, dried under vacuum, and dissolved in toluene $(15 \mathrm{~mL})$. To this solution was added diol $8(0.26 \mathrm{~g}, 0.98 \mathrm{mmol})$ in toluene $(5 \mathrm{~mL})$ and DMAP $(0.16 \mathrm{~g}, 1.33 \mathrm{mmol})$. After stirring for $16 \mathrm{~h}$ at $\mathrm{rt}$, the reaction 
mixture was diluted with EtOAc $(50 \mathrm{~mL})$, washed with sat'd aq. $\mathrm{NaHCO}_{3}(20 \mathrm{~mL})$, dried $\left(\mathrm{Na}_{2} \mathrm{SO}_{4}\right)$ and filtered. The solvent was evaporated under reduced pressure, and the residue was purified by flash chromatography eluting with EtOAc/hexanes (0.4/1) to afford $0.68 \mathrm{~g}$ (75\%) of $\mathbf{4 4}$ as a colorless oil. $[\alpha]^{23} \mathrm{D}+27.4^{\circ}\left(c 0.7, \mathrm{CH}_{2} \mathrm{Cl}_{2}\right)$; IR (film) 3460, 2951, 2933, 2878, 1732, 1471, 1462, 1381, 1254, 1199, 1095, 1073, 1044, 1005, 949, 834, 774, 736 $\mathrm{cm}^{-1} ;{ }_{1}^{1} \mathrm{H}$ NMR $(400 \mathrm{MHz}) \delta 6.54(\mathrm{~d}, J=14.4 \mathrm{~Hz}, 1 \mathrm{H}), 6.41(\mathrm{~d}, J=14.4,1 \mathrm{H}), 4.78(\mathrm{dd}, J=$ 9.6, 3.2 Hz, 1H), $4.48(\mathrm{dt}, J=9.6,3.2 \mathrm{~Hz}, 1 \mathrm{H}), 3.60-3.55(\mathrm{~m}, 3 \mathrm{H}), 3.10(\mathrm{~s}, 3 \mathrm{H}), 2.67-2.62$ (m, 1H), 2.33 (bs, $1 \mathrm{H}), 1.79-1.34(\mathrm{~m}, 8 \mathrm{H}), 1.23(\mathrm{~s}, 3 \mathrm{H}), 1.17$ (d, J = 6.8 Hz, 3H), 1.02 (s, $3 \mathrm{H}), 0.94(\mathrm{t}, J=8 \mathrm{~Hz}, 9 \mathrm{H}), 0.88-0.86(\mathrm{~m}, 12 \mathrm{H}), 0.84(\mathrm{~s}, 9 \mathrm{H}), 0.66-0.55(\mathrm{~m}, 6 \mathrm{H}), 0.06(\mathrm{~s}$, $3 \mathrm{H}), 0.03(\mathrm{~s}, 6 \mathrm{H}) ;{ }^{13} \mathrm{C} \mathrm{NMR}(100 \mathrm{MHz}) \delta 175.0,147.6,80.0,79.0,77.6,77.2,73.6,69.6$, 63.2, 48.3, 42.7, 37.3, 29.4, 26.0, 25.9 (6C), 25.2, 22.6, 18.2, 18.0, 17.4, 10.6, 9.6, 7.2 (3C), $5.4(3 \mathrm{C}),-3.8,-4.6,-5.4(2 \mathrm{C})$; HRMS (FAB) calc'd for $\mathrm{C}_{37} \mathrm{H}_{77} \mathrm{IO}_{7} \mathrm{Si}_{3}+\mathrm{Na}=867.3920$ found 867.3900 .

$(2 R, 3 S, 5 R, 6 R)-(3 R, 4 S, E)-4$-hydroxy-6-iodo-4-methylhex-5-en-3-yl 3-((tertbutyldimethylsilyl)oxy)-9-hydroxy-6-methoxy-2,6-dimethyl-5-((triethylsilyl)oxy)nonanoate (45). To a solution of $\mathrm{TBAF} \cdot 3 \mathrm{H}_{2} \mathrm{O}(0.90 \mathrm{~g}, 2.86 \mathrm{mmol})$ in $\mathrm{DMF}(28 \mathrm{~mL})$ was added $\mathrm{AcOH}$ $(0.70 \mathrm{~g}, 2.01 \mathrm{mmol})$. After stirring for $30 \mathrm{~min}$, the solution was added to $44(0.68 \mathrm{~g}, 0.95$ $\mathrm{mmol}$ ), and the reaction mixture was stirred for $20 \mathrm{~h}$ at rt. The reaction was quenched with $\mathrm{H}_{2} \mathrm{O}(20 \mathrm{~mL})$, and the aqueous layer was back-extracted with $\mathrm{Et}_{2} \mathrm{O}(4 \times 60 \mathrm{~mL})$. The combined organic layers were washed with sat'd aq. $\mathrm{NaHCO}_{3}(50 \mathrm{~mL}), \mathrm{H}_{2} \mathrm{O}(50 \mathrm{~mL})$, brine $(50 \mathrm{~mL})$, dried $\left(\mathrm{Na}_{2} \mathrm{SO}_{4}\right)$ and filtered. The solvent was concentrated under reduced pressure, and the residue was purified by flash chromatography eluting with EtOAc/hexanes (1/5) to afford $0.35 \mathrm{~g}(60 \%)$ of $\mathbf{4 5}$ as a colorless oil. $[\alpha]^{23} \mathrm{D}+30.8^{\circ}\left(c 0.6, \mathrm{CH}_{2} \mathrm{Cl}_{2}\right)$; IR (film) 3458, 2951, 2936, 2909, 2877, 1729, 1461, 1251, 1192, 1095, 1069, 1044, 1004, 950, 940, 836, $775 \mathrm{~cm}^{-1} ;{ }^{1} \mathrm{H}$ NMR $(400 \mathrm{MHz}) \delta 6.55(\mathrm{~d}, J=14.4 \mathrm{~Hz}, 1 \mathrm{H}), 6.41(\mathrm{~d}, J=14.4,1 \mathrm{H}), 4.77(\mathrm{dd}$, $J=10.0,3.2 \mathrm{~Hz}, 1 \mathrm{H}), 4.45(\mathrm{dt}, J=9.6,3.2 \mathrm{~Hz}, 1 \mathrm{H}), 3.66(\mathrm{dd}, J=10.4,2.0 \mathrm{~Hz}, 1 \mathrm{H})$, $3.62-3.58(\mathrm{~m}, 2 \mathrm{H}), 3.14(\mathrm{~s}, 3 \mathrm{H}), 2.67(\mathrm{dq}, J=4.8,2.4 \mathrm{~Hz}, 1 \mathrm{H}), 2.55(\mathrm{bs}, 1 \mathrm{H}), 2.03(\mathrm{~m}, 1 \mathrm{H})$, $1.82-1.42(\mathrm{~m}, 8 \mathrm{H}), 1.23(\mathrm{~s}, 3 \mathrm{H}), 1.18(\mathrm{~d}, J=7.2 \mathrm{~Hz}, 3 \mathrm{H}), 1.05(\mathrm{~s}, 3 \mathrm{H}), 0.94(\mathrm{t}, J=8.0 \mathrm{~Hz}$, 9H), 0.86-0.84 (m, 12H), 0.66-0.55 (m, 6H), 0.77 (s, 3H), 0.05 (s, 3H); ${ }^{13} \mathrm{C}$ NMR $(100$ $\mathrm{MHz}) \delta 175.0,147.6,80.1,79.3,77.5,77.3,73.5,69.8,63.2,48.6,43.4,37.7,30.2,26.2$, 25.9 (3C), 24.9, 22.7, 18.1, 17.4, 10.6, 10.3, 7.1 (3C), 5.4 (3C), -3.9, -4.7; HRMS (FAB) calc'd for $\mathrm{C}_{31} \mathrm{H}_{63} \mathrm{IO}_{7} \mathrm{Si}_{2}+\mathrm{Na}=753.3055$ found 753.3032 .

$(2 R, 3 S, 5 R, 6 R)-(3 R, 4 S, E)-4-h y d r o x y-6-i o d o-4-m e t h y l h e x-5-e n-3-y l ~ 3-((t e r t-$ butyldimethylsilyl)oxy)-6-methoxy-2,6-dimethyl-9-oxo-5-((triethylsilyl)oxy)nonanoate (46). Dess-Martin periodinane $(0.23 \mathrm{~g}, 0.54 \mathrm{mmol})$ and $\mathrm{NaHCO}_{3}(0.19 \mathrm{~g}, 2.25 \mathrm{mmol})$ were suspended in $\mathrm{CH}_{2} \mathrm{Cl}_{2}(3 \mathrm{~mL})$. Alcohol $45(0.33 \mathrm{~g}, 0.45 \mathrm{mmol})$ in $\mathrm{CH}_{2} \mathrm{Cl}_{2}(4 \mathrm{~mL})$ was added dropwise via cannula into the reaction mixture. After $1 \mathrm{~h}$ at $\mathrm{rt}$, the reaction mixture was added to a mixture of sat'd aq. $\mathrm{NaHCO}_{3}(5 \mathrm{~mL})$, sat'd aq. $\mathrm{Na}_{2} \mathrm{SO}_{3}(5 \mathrm{~mL})$ and $\mathrm{H}_{2} \mathrm{O}(10$ $\mathrm{mL})$. The mixture was extracted with $\mathrm{Et}_{2} \mathrm{O}(2 \times 20 \mathrm{~mL})$. The combined organic layers were washed with brine $(10 \mathrm{~mL})$, dried $\left(\mathrm{Na}_{2} \mathrm{SO}_{4}\right)$ and filtered. The solvent was concentrated under reduced pressure, and the residue was purified by flash chromatography eluting with EtOAc/hexanes (1/5) to afford $0.28 \mathrm{~g}$ (78\% yield) of $\mathbf{4 6}$ as a colorless oil. $[\alpha]^{23} \mathrm{D}+32.8^{\circ}(c$ $0.7, \mathrm{CH}_{2} \mathrm{Cl}_{2}$ ); IR (film) 2952, 2879, 2877, 1733, 1684, 1463, 1411, 1379, 1250, 1190, 1094, $1050 \mathrm{~cm}^{-1} ;{ }^{1} \mathrm{H}$ NMR $(400 \mathrm{MHz}) \delta 9.76(\mathrm{~m}, 1 \mathrm{H}), 6.55(\mathrm{~d}, J=14.4 \mathrm{~Hz}, 1 \mathrm{H}), 6.41(\mathrm{~d}, J=14.4$ $\mathrm{Hz}, 1 \mathrm{H}), 4.78(\mathrm{dd}, J=10.0,3.2 \mathrm{~Hz}, 1 \mathrm{H}), 4.44(\mathrm{dt}, J=8.8,3.6 \mathrm{~Hz}, 1 \mathrm{H}), 3.59$ (dd, $J=9.6,2.4$ $\mathrm{Hz}, 1 \mathrm{H}), 3.10$ (s, 3H), 2.67 (dq, $J=4.8,2.4 \mathrm{~Hz}, 1 \mathrm{H}), 2.53-2.35(\mathrm{~m}, 3 \mathrm{H}), 1.99-1.91(\mathrm{~m}, 1 \mathrm{H})$, 1.77-1.47 (m, 6H), $1.24(\mathrm{~s}, 3 \mathrm{H}), 1.17(\mathrm{~d}, J=7.2 \mathrm{~Hz}, 3 \mathrm{H}), 1.08(\mathrm{~s}, 3 \mathrm{H}), 0.95(\mathrm{t}, J=8.4 \mathrm{~Hz}$, 9H), 0.87-0.85 (m, 12H), 0.66-0.55 (m, 6H), 0.07 (s, 3H), 0.05 (s, 3H); ${ }^{13} \mathrm{C}$ NMR (100 MHz) $\delta 202.1,174.8,147.6,80.1,78.6,77.5,77.2,73.4,69.8,48.8,43.3,38.0,37.6,25.8$ (3C), 25.6, 24.9, 22.7, 18.1, 17.7, 10.6, 10.2, 7.1 (3C), 5.4 (3C), -3.9, -4.6; HRMS (FAB) calc'd for $\mathrm{C}_{31} \mathrm{H}_{61} \mathrm{IO}_{7} \mathrm{Si}_{2}+\mathrm{Na}=751.2898$ found 751.2892. 
(3R,4S,6R,7R,13S,14R,E)-4-((tert-butyldimethylsilyl)oxy)-14-ethyl-10,13-dihydroxy-7methoxy-3,7,13-trimethyl-6-((triethylsilyl)oxy)oxacyclotetradec-11-en-2-one (47). To a solution of aldehyde $46(0.28 \mathrm{~g}, 0.27 \mathrm{mmol})$ in DMSO $(158 \mathrm{~mL})$ at $\mathrm{rt}$ was added $\mathrm{CrCl}_{2}$ $(0.47 \mathrm{~g}, 3.84 \mathrm{mmol})$ and $\mathrm{NiCl}_{2}(0.005 \mathrm{mg}, 0.038 \mathrm{mmol})$. The reaction mixture was stirred for $16 \mathrm{~h}$ then quenched by the addition of $\mathrm{H}_{2} \mathrm{O}(90 \mathrm{~mL})$. The mixture was diluted with EtOAc $(600 \mathrm{~mL})$, and the layers were separated. The organic layer was washed with $\mathrm{H}_{2} \mathrm{O}(3 \times 100$ $\mathrm{mL})$. The combined aqueous layers were back-extracted with EtOAc $(3 \times 200 \mathrm{~mL})$. The combined organic layers were washed with brine $(200 \mathrm{~mL})$, dried $\left(\mathrm{Na}_{2} \mathrm{SO}_{4}\right)$ and filtered. The solvent was concentrated under reduced pressure, and the residue was purified by flash chromatography eluting with EtOAc/hexanes (2/5) to afford $0.12 \mathrm{~g} \mathrm{(dr}=1: 1$ at C9) (50\%) of 47 as a foam. IR (film) 3443, 2953, 2936, 2909, 2878, 1731, 1461, 1251, 1095, 1057, 1005, $972,854,831,815,774 \mathrm{~cm}^{-1} ;{ }^{1} \mathrm{H}$ NMR $(400 \mathrm{MHz}) \delta 5.75-5.60(\mathrm{~m}, 2 \mathrm{H}), 4.81(\mathrm{td}, J=10.6$, $2.0 \mathrm{~Hz}, 1 \mathrm{H}), 4.30-4.12(\mathrm{~m}, 1 \mathrm{H}), 4.07-3.98(\mathrm{~m}, 1 \mathrm{H}), 3.14(\mathrm{~s}, 3 \mathrm{H}), 2.69-2.46(\mathrm{~m}, 2 \mathrm{H})$, 2.19-1.73 (m, 2H), 1.53-133 (m, 4H), 1.29-1.26 (m, 3H), 1.21-1.16 (m, 3H), 1.12-1.03 (m, $3 \mathrm{H}), 0.97-0.89(\mathrm{~m}, 12 \mathrm{H}), 0.87-0.84(\mathrm{~s}, 9 \mathrm{H}), 0.64-0.53(\mathrm{~m}, 6 \mathrm{H}), 0.10-0.01(\mathrm{~m}, 6 \mathrm{H}) ;{ }^{13} \mathrm{C}$ NMR $(100 \mathrm{MHz}) \delta 175.7,175.3,136.2,133.7,133.2,132.4,80.3,79.6,79.4,79.3,74.4,73.9$, $73.7,73.4,72.9,72.6,70.5,70.3,48.7,48.3,42.5,40.4,30.6,30.5,29.6,27.5,26.1,25.8$, 23.3, 22.1, 20.6, 19.1, 18.3, 18.0, 17.4, 15.5, 15.0, 10.6, 10.6, 7.1, 7.0, 5.3, 5.1, -3.4, -4.1, $-4.8,-5.0$; HRMS (FAB) calc'd for $\mathrm{C}_{31} \mathrm{H}_{62} \mathrm{O}_{7} \mathrm{Si}_{2}+\mathrm{Na}=625.3932$, found 625.3911.

(1R,3S,4R,7R,8S,14R,E)-3-((tert-butyldimethylsilyl)oxy)-7-ethyl-8,11-dihydroxy-14methoxy-4,8,14-trimethyl-6,15-dioxabicyclo[9.3.1]pentadec-9-en-5-one (53). To a solution of $48(0.030 \mathrm{~g}, 0.05 \mathrm{mmol})$ in $\mathrm{MeOH}(7 \mathrm{~mL})$ was added $p-\mathrm{TsOH}(2 \mathrm{mg}, 0.01 \mathrm{mmol})$ at $0{ }^{\circ} \mathrm{C}$. After $3 \mathrm{~h}$ at this temperature, the reaction was quenched by adding sat'd aq. $\mathrm{NaHCO}_{3}(5$ $\mathrm{mL})$. The reaction mixture was diluted with EtOAc $(20 \mathrm{~mL})$ and the aqueous layer was back-extracted with EtOAc $(2 \times 5 \mathrm{~mL})$. The combined organic layers were washed with brine $(10 \mathrm{~mL})$, dried $\left(\mathrm{Na}_{2} \mathrm{SO}_{4}\right)$ and filtered. The solvent was concentrated under reduced pressure and purified directly by flash chromatography eluting with hexanes/EtOAc (4:1) to afford $12 \mathrm{mg}(52 \%)$ of $\mathbf{5 3}$ as a foam. $[\alpha]^{23} \mathrm{D}+10.7^{\circ}\left(c 0.8, \mathrm{CH}_{2} \mathrm{Cl}_{2}\right)$; IR (film) 3441,2954 , 2934, 2882, 1729, 1461, 1374, 1264, 1178, 1145, 1072, 1006, 961, 834, 775, $702 \mathrm{~cm}^{-1} ;{ }^{1} \mathrm{H}$ NMR $(400 \mathrm{MHz}) \delta 6.07(\mathrm{~d}, J=16.4 \mathrm{~Hz}, 1 \mathrm{H}), 5.95(\mathrm{~d}, J=16.4 \mathrm{~Hz}, 1 \mathrm{H}), 4.85(\mathrm{t}, J=3.6 \mathrm{~Hz}$, $1 \mathrm{H}), 4.54(\mathrm{dd}, J=11.2,2.4 \mathrm{~Hz}, 1 \mathrm{H}), 4.29(\mathrm{~d}, J=9.6 \mathrm{~Hz}, 1 \mathrm{H}), 3.94-3.90(\mathrm{~m}, 1 \mathrm{H}), 3.21(\mathrm{~s}$, $3 \mathrm{H}), 2.90-2.82(\mathrm{~m}, 1 \mathrm{H}), 2.06-1.95(\mathrm{~m}, 3 \mathrm{H}), 1.85-1.71(\mathrm{~m}, 2 \mathrm{H}), 1.57-1.46(\mathrm{~m}, 2 \mathrm{H}), 2.59$ (bs, $2 \mathrm{H}), 1.30(\mathrm{~s}, 3 \mathrm{H}), 1.27(\mathrm{~d}, J=6.8 \mathrm{~Hz}, 3 \mathrm{H}), 1.27(\mathrm{~s}, 3 \mathrm{H}), 0.88(\mathrm{t}, J=7.2 \mathrm{~Hz}, 3 \mathrm{H}), 0.90$ (s, 9H), $0.08(\mathrm{~s}, 3 \mathrm{H}), 0.05(\mathrm{~s}, 3 \mathrm{H}) ;{ }^{13} \mathrm{C}$ NMR $(100 \mathrm{MHz}) \delta 175.4,146.1,136.3,122.8,102.9$, 83.2, 74.7, 73.6, 71.7, 70.9, 49.1, 44.4, 31.3, 29.3, 25.9 (3C), 21.6, 21.2, 18.0, 16.4, 10.5, $-4.1,-4.7$; HRMS (FAB) calc'd for $\mathrm{C}_{25} \mathrm{H}_{46} \mathrm{O}_{7} \mathrm{Si}+\mathrm{K}=525.2650$, found 525.2667.

$(3 R, 4 S, 6 R, 7 R, 13 S, 14 R, E)$-14-ethyl-4,6,13-trihydroxy-7-methoxy-3,7,13trimethyloxacyclotetradec-11-ene-2,10-dione (54). To a solution of 48 (34 mg, $0.05 \mathrm{mmol})$ in THF $(2.2 \mathrm{~mL})$ was added TBAF• $3 \mathrm{H}_{2} \mathrm{O}(54 \mathrm{mg}, 0.17 \mathrm{mmol})$ at $0{ }^{\circ} \mathrm{C}$ and allowed to slowly warm to $10^{\circ} \mathrm{C}$ and stirred for $6 \mathrm{~h}$. The reaction mixture was quenched by slowly adding sat'd aq. $\mathrm{NaHCO}_{3}(3 \mathrm{~mL})$. The mixture was diluted with EtOAc $(5 \mathrm{~mL})$, and the aqueous layer was extracted with EtOAc $(2 \times 5 \mathrm{~mL})$. The combined organic layers were washed with brine $(10 \mathrm{~mL})$, dried $\left(\mathrm{Na}_{2} \mathrm{SO}_{4}\right)$ and filtered. The solvent was concentrated under reduced pressure, and the residue was purified by flash chromatography eluting with EtOAc/hexanes (3:2) to afford $13 \mathrm{mg}$ of $\mathbf{5 4}(70 \%)$ as a foam. $[\alpha]^{23} \mathrm{D}+3.5^{\circ}\left(c 0.9, \mathrm{CH}_{2} \mathrm{Cl}_{2}\right)$; IR (film) 3441,2956 , $2878,1727,1462,1372,1265,1178,1093 \mathrm{~cm}^{-1} ;{ }^{1} \mathrm{H}$ NMR $(400 \mathrm{MHz}) \delta 6.74(\mathrm{~d}, J=16.0$ $\mathrm{Hz}, 1 \mathrm{H}), 6.19(\mathrm{~d}, J=16.0 \mathrm{~Hz}, 1 \mathrm{H}), 4.87(\mathrm{dd}, J=10.8,2.4 \mathrm{~Hz}, 1 \mathrm{H}), 4.00(\mathrm{t}, J=8.8 \mathrm{~Hz}, 1 \mathrm{H})$, 3.86 (dd, $J=10.8,2.4 \mathrm{~Hz}, 1 \mathrm{H}), 3.72$ (bs, 1H), $3.20(\mathrm{~s}, 3 \mathrm{H}), 2.88(\mathrm{bs}, 1 \mathrm{H}), 2.65-2.53(\mathrm{~m}, 3 \mathrm{H})$, 2.31-2.23 (m, 1H), 12.95-1.84 (m, 2H), 1.74-1.46 (m, 5H), $1.33(\mathrm{~s}, 3 \mathrm{H}), 1.30(\mathrm{~d}, J=6.8 \mathrm{~Hz}$, $3 \mathrm{H}), 1.01(\mathrm{~s}, 3 \mathrm{H}), 0.91(\mathrm{t}, J=7.2 \mathrm{~Hz}, 3 \mathrm{H}) ;{ }^{13} \mathrm{C}$ NMR $(100 \mathrm{MHz}) \delta 202.2,175.9,150.4$, 
128.3, 79.9, 78.7, 73.8, 73.2, 48.9, 46.8, 37.1, 33.5, 30.6, 22.0, 21.8, 20.8, 16.2, 14.1, 10.4; HRMS (FAB) calc'd for $\mathrm{C}_{19} \mathrm{H}_{32} \mathrm{O}_{7}+\mathrm{Na}=395.2046$ found 395.2024.

(3R,4S,6R,7R,10R,13S,14R,E)-4-((tert-butyldimethylsilyl)oxy)-14-ethyl-6,10,13trihydroxy-7-methoxy-3,7,13-trimethyloxacyclotetradec-11-en-2-one (55). To a solution of $48(0.075 \mathrm{~g}, 0.12 \mathrm{mmol})$ in $\mathrm{MeOH}(3 \mathrm{~mL})$ at $\mathrm{rt}$ was added $\mathrm{CeCl}_{3} \cdot 7 \mathrm{H}_{2} \mathrm{O}(53 \mathrm{mg}, 0.14 \mathrm{mmol})$. The reaction mixture was cooled to $-60{ }^{\circ} \mathrm{C}$ after which $\mathrm{NaBH}_{4}(5.3 \mathrm{mg}, 0.14 \mathrm{mmol})$ was added. After $30 \mathrm{~min}$ at this temperature, the reaction was quenched by adding sat'd aq. $\mathrm{NH}_{4} \mathrm{Cl}(2 \mathrm{~mL})$. Ethyl acetate $(10 \mathrm{~mL})$ was added, and the aqueous layer was back-extracted with EtOAc $(2 \times 5 \mathrm{~mL})$. The combined organic layers were washed with $1 \mathrm{~N} \mathrm{HCl}$ solution $(5$ $\mathrm{mL})$, sat'd aq. $\mathrm{NaHCO}_{3}(5 \mathrm{~mL}), \mathrm{H}_{2} \mathrm{O}(5 \mathrm{~mL})$, brine $(5 \mathrm{~mL})$, dried $\left(\mathrm{Na}_{2} \mathrm{SO}_{4}\right)$ and filtered. The solvent was concentrated under reduced pressure, and the residue was dried under vacuum. The residue was dissolved in $\mathrm{MeOH}(17 \mathrm{~mL})$ and cooled to $0{ }^{\circ} \mathrm{C}$ after which $p$ $\mathrm{TsOH}(4.5 \mathrm{mg}, 0.024 \mathrm{mmol})$ was added. The reaction mixture was stirred at $0{ }^{\circ} \mathrm{C}$ for $3 \mathrm{~h}$ after which the reaction was quenched by adding $\mathrm{NaHCO}_{3}(10 \mathrm{mg})$. The mixture was concentrated and purified directly by flash chromatography eluting with EtOAc/hexanes $(2 / 5)$ to afford $44 \mathrm{mg}$ of $\mathbf{5 5}(75 \%)$ as a foam. ( $\mathrm{dr}=7: 1 \mathrm{dr}$ at $\mathrm{C} 9$ by ${ }^{1} \mathrm{H}$ NMR). Major 9-( $R$ ) isomer: IR (film) 3441, 2956, 2878, 1727, 1462, 1372, 1265, 1178, $1093 \mathrm{~cm}^{-1} ;{ }^{1} \mathrm{H}$ NMR $(400 \mathrm{MHz}) \delta 5.90-5.84(\mathrm{~m}, 1 \mathrm{H}), 5.71(\mathrm{~m}, 1 \mathrm{H}), 4.87-4.84(\mathrm{~m}, 1 \mathrm{H}), 4.13-4.04(\mathrm{~m}, 2 \mathrm{H})$, 3.75-3.73 (m, 1H), $3.20(\mathrm{~s}, 3 \mathrm{H}), 2.80-2.70(\mathrm{~m}, 2 \mathrm{H}), 2.52$ (bs, 1H), 2.13 (bs, 1H), 2.02-1.96 $(\mathrm{m}, 1 \mathrm{H}), 1.83-1.42(\mathrm{~m}, 5 \mathrm{H}), 1.30(\mathrm{~s}, 3 \mathrm{H}), 1.22(\mathrm{~m}, 1 \mathrm{H}), 1.26(\mathrm{~s}, 3 \mathrm{H}), 1.22(\mathrm{~d}, J=6.4 \mathrm{~Hz}$, $3 \mathrm{H}), 1.07(\mathrm{~s}, 3 \mathrm{H}), 0.93(\mathrm{t}, J=7.2 \mathrm{~Hz}, 3 \mathrm{H}), 0.87(\mathrm{~s}, 9 \mathrm{H}), 0.10(\mathrm{~s}, 6 \mathrm{H}) ;{ }^{13} \mathrm{C} \mathrm{NMR}(100 \mathrm{MHz}) \delta$ 175.4, 133.7, 133.2, 81.5, 78.6, 73.9, 72.6, 72.1, 71.7, 49.4, 48.0, 37.2, 31.0, 29.6, 27.6, 25.8 (3C), 24.5, 23.5, 17.5, 15.1, 10.8, -4.6, -4.7; HRMS (FAB) calc'd for $\mathrm{C}_{25} \mathrm{H}_{48} \mathrm{O}_{7} \mathrm{Si}+\mathrm{Na}=$ 511.3067, found 511.3042.

$(2 S, 3 R, 4 R, 6 S)-2-(((2 R, 3 S, 6 R, 9 R, 10 R, 12 S, 13 R, E)-12-(($ tert-butyldimethylsilyl)oxy)-2ethyl-10-hydroxy-9-methoxy-3,9,13-trimethyl-14-oxo-6((triethylsilyl)oxy)oxacyclotetradec-4-en-3-yl)oxy)-4-(dimethylamino)-6methyltetrahydro-2 $\mathrm{H}$-pyran-3-yl methyl carbonate (57). To a solution of 55 (70 mg, 0.14 $\mathrm{mmol})$ in DMF $(1.5 \mathrm{~mL})$ and $\mathrm{CH}_{2} \mathrm{Cl}_{2}(1.5 \mathrm{~mL})$ at $\mathrm{rt}$ were added imidazole $(12 \mathrm{mg}, 0.16$ $\mathrm{mmol})$ and DMAP $(2 \mathrm{mg})$. The reaction mixture was cooled to $-78^{\circ} \mathrm{C}$, and TESCl $(25 \mathrm{mg}$, $0.15 \mathrm{mmol}$ ) was added. After stirring for $3 \mathrm{~h}$ at $-78^{\circ} \mathrm{C}$ the reaction was quenched by adding sat'd aq. $\mathrm{NH}_{4} \mathrm{Cl}(3 \mathrm{~mL})$. The mixture was diluted with EtOAc $(10 \mathrm{~mL})$, and the aqueous layer was back-extracted with EtOAc $(2 \times 5 \mathrm{~mL})$. The combined organic layers were washed with $\mathrm{H}_{2} \mathrm{O}(5 \mathrm{~mL})$, dried $\left(\mathrm{Na}_{2} \mathrm{SO}_{4}\right)$ and filtered. The solvent was concentrated under reduced pressure, azeotroped with toluene $(5 \mathrm{~mL})$, and the crude alcohol was taken to the next step. To a suspension of freshly activated $4 \AA$ molecular sieves $(1.55 \mathrm{~g})$ and $\operatorname{AgOTf}(0.72 \mathrm{~g}, 2.82$ mmol) in $\mathrm{CH}_{2} \mathrm{Cl}_{2}$ /toluene ( $\left.5 \mathrm{~mL}, 1: 1\right)$ was added dropwise by cannula a mixture of $\mathrm{C} 5$ alcohol $(0.14 \mathrm{mmol})$, desosamine donor $7(0.28 \mathrm{~g}, 0.85 \mathrm{mmol})$ and 2,6-di-tert-butyl-4methylpyridine $(0.18 \mathrm{~g}, 0.85 \mathrm{mmol})$ in $\mathrm{CH}_{2} \mathrm{Cl}_{2}(2.5 \mathrm{~mL})$ at $0{ }^{\circ} \mathrm{C}$. The reaction flask was wrapped with aluminum foil, warmed to rt and stirred for an additional $20 \mathrm{~h}$. The reaction was quenched with $\mathrm{Et}_{3} \mathrm{~N}$ ( $\left.4.0 \mathrm{~mL}\right)$, filtered through Celite, and eluted with EtOAc $(50 \mathrm{~mL})$. The filtrate was washed with sat'd aq. $\mathrm{NaHCO}_{3}(20 \mathrm{~mL})$, dried $\left(\mathrm{Na}_{2} \mathrm{SO}_{4}\right)$, filtered, and concentrated under reduced pressure. The residue was purified by flash chromatography eluting with hexanes/EtOAc (3:2) to afford $42 \%$ of $\mathbf{5 7}$ as a foam $\left(\mathrm{dr}=7: 1 \mathrm{dr}\right.$ at $\mathrm{C} 9$ by ${ }^{1} \mathrm{H}$ NMR). Major 9-( $R$ ) isomer: IR (film) 3441, 2956, 2878, 1727, 1462, 1372, 1265, 1178, $1093 \mathrm{~cm}^{-1} ;{ }^{1} \mathrm{H}$ NMR $(400 \mathrm{MHz}) \delta 5.80(\mathrm{~m}, 1 \mathrm{H}), 5.48(\mathrm{~d}, J=16.4 \mathrm{~Hz}, 1 \mathrm{H}), 5.15(\mathrm{dd}, J=$ $10.0,1.6 \mathrm{~Hz}, 1 \mathrm{H}), 4.55(\mathrm{dd}, J=10.4,7.6 \mathrm{~Hz}, 1 \mathrm{H}), 4.48(\mathrm{~d}, J=7.6 \mathrm{~Hz}, 1 \mathrm{H}), 3.96-3.93(\mathrm{~m}$, $2 \mathrm{H}), 3.77(\mathrm{~s}, 3 \mathrm{H}), 3.72-3.68(\mathrm{~m}, 1 \mathrm{H}), 3.47-3.43(\mathrm{~m}, 1 \mathrm{H}), 3.18(\mathrm{~s}, 3 \mathrm{H}), 2.75-2.56(\mathrm{~m}, 2 \mathrm{H})$, $2.27(\mathrm{~m}, 9 \mathrm{H}), 2.33-2.30(\mathrm{~m}, 1 \mathrm{H}), 1.26(\mathrm{~s}, 3 \mathrm{H}), 1.21(\mathrm{~d}, J=6.8 \mathrm{~Hz}, 3 \mathrm{H}), 1.22(\mathrm{~d}, J=6.0 \mathrm{~Hz}$, $3 \mathrm{H}), 1.04(\mathrm{~s}, 3 \mathrm{H}), 0.95(\mathrm{t}, J=8.0 \mathrm{~Hz}, 9 \mathrm{H}), 0.88(\mathrm{~s}, 9 \mathrm{H}), 0.85(\mathrm{t}, J=11.4 \mathrm{~Hz}, 3 \mathrm{H}), 0.62-0.52$ $(\mathrm{m}, 6 \mathrm{H}), 0.12(\mathrm{~s}, 3 \mathrm{H}), 0.10(\mathrm{~s}, 3 \mathrm{H}) ;{ }^{13} \mathrm{C}$ NMR $(100 \mathrm{MHz}) \delta 174.3,153.3,135.8,131.2,96.6$, 
79.7, 78.7, 77.8, 75.1, 73.9, 73.6, 73.0, 68.8, 63.0, 54.6, 49.1, 48.6, 40.6 (2C), 37.7, 31.7, 30.8, 29.6, 28.1, 25.8(3C), 22.9, 21.2, 20.6, 18.0, 15.6, 10.6, 6.9 (3C), 5.0 (3C), -4.2, -4.4; HRMS (FAB) calc'd for $\mathrm{C}_{41} \mathrm{H}_{79} \mathrm{NO}_{11} \mathrm{Si}_{2}+\mathrm{Na}=840.5089$, found 840.5081 .

\section{Supplementary Material}

Refer to Web version on PubMed Central for supplementary material.

\section{Acknowledgments}

We thank Dr. Richard Pederson (Materia, Inc.) for catalyst support. Finally, this work was supported by the NIH (AI080968).

\section{References and Notes}

1. Doern GV, Heilmann KP, Huynh HK, Rhomberg PR, Coffman SL, Brueggemann AB. Antimicrob. Agents Chemother. 2001; 45:1721. [PubMed: 11353617]

2. (a) Fox JL. Nat. Biotechnol. 2006; 24:1521. [PubMed: 17160056] (b) Walsh CT. Nat. Rev. Microbiol. 2003; 1:65. [PubMed: 15040181]

3. Tu D, Blaha G, Moore PB, Steitz TA. Cell. 2005; 121:257. [PubMed: 15851032]

4. Ma XD, Ma ST. Curr. Med. Chem. 2011; 18:1993. [PubMed: 21517774]

5. Velvadapu V, Paul T, Wagh B, Klepacki D, Guvench O, MacKerell A, Andrade RB. ACS Med. Chem. Lett. 2010; 2:68. [PubMed: 21643527]

6. Baker WR, Clark JD, Stephens RL, Kim KH. J. Org. Chem. 1988; 53:2340.

7. Denis A, Agouridas C, Auger J-M, Benedeti Y, Bonnefoy A, Bretin F, Chantot F, Dussarat A, Fromentin C, D’Ambrieres SG, Lachaud S, Laurin P, Le Martret O, Loyau V, Tessot N, Pejac J-M, Perron S. Bioorg. Med. Chem. Lett. 1999; 9:3075. [PubMed: 10560728]

8. (a) Woodward RB, Logusch E, Nambiar KP, Sakan K, Ward DE, Auyeung BW, Balaram P, Browne LJ, Card PJ, Chen CH, Chenevert RB, Fliri A, Frobel K, Gais HJ, Garratt DG, Hayakawa K, Heggie W, Hesson DP, Hoppe D, Hoppe I, Hyatt JA, Ikeda D, Jacobi PA, Kim KS, Kobuke Y, Kojima K, Krowicki K, Lee VJ, Leutert T, Malchenko S, Martens J, Mathews RS, Ong BS, Press JB, RajanBabu TV, Rousseau G, Sauter HM, Suzuki M, Tatsuta K, Tolbert LM, Truesdale EA, Uchida I, Ueda Y, Uyehara T, Vasella AT, Vladuchick WC, Wade PA, Williams RM, Wong HNC. J. Am. Chem. Soc. 1981; 103:3215.(b) Velvadapu V, Andrade RB. Carb. Res. 2008; 343:145.

9. Venkatraman L, Salomon CE, Sherman DE, Fecik RA. J. Org. Chem. 2006; 71:9853. [PubMed: 17168607]

10. Xuan R, Oh H-S, Lee Y, Kang H-Y. J. Org. Chem. 2008; 73:1456. [PubMed: 18205385]

11. Inanaga J, Hirata K, Saeki H, Katsuki T, Yamaguchi M. Bull. Chem. Soc. Jpn. 1979; 52:1989.

12. Evans DA, Bartroli J, Shih TL. J. Am. Chem. Soc. 1981; 103:2127.

13. Kolb HC, Van Nieuwenhze MS, Sharpless KB. Chem. Rev. 1994; 94:2483.

14. Sharpless KB, Hanson RM. J. Org. Chem. 1986; 51:1922.

15. Martin SF, Lee W-C, Pacofsky GJ, Gist RP, Mulhern TA. J. Am. Chem. Soc. 1994; 116:4674.

16. Oh HS, Xuan R, Kang H-Y. Org. Biomol. Chem. 2009; 7:4458. [PubMed: 19830295]

17. Corey EJ, Fuchs PL. Tetrahedron Lett. 1972; 13:3769.

18. Yadav JS, Pratap TV, Rajender V. J. Org. Chem. 2007; 72:5882. [PubMed: 17602529]

19. Johnson WS, Werthemann L, Bartlett WR, Brocksom TJ, Li T-T, Faulkner DJ, Petersen MR. J. Am. Chem. Soc. 1970; 92:741.

20. Rucker C. Chem. Rev. 1995; 95:1009.

21. Hillier MC, Meyers AI. Tetrahedron Lett. 2001; 42:5145-5147. and references cited therein.

22. Dess DB, Martin JC. J. Org. Chem. 1983; 48:4155.

23. 2D NMR experiments were used to confirm this structure.

24. Xuan R, Oh H-S, Lee Y, Kang H-Y. J. Org. Chem. 2008; 73:1456-1461. [PubMed: 18205385]

J Org Chem. Author manuscript; available in PMC 2012 September 16. 
25. Scholl M, Ding S, Lee CW, Grubbs RH. Org. Lett. 1999; 1:953-956. [PubMed: 10823227]

26. Hergenrother PJ, Hodgson A, Judd AS, Lee W-C, Martin SF. Angew. Chem. Int. Ed. 2003; 42:3278.

27. Toshima K, Nozaki Y, Mukaiyama S, Tamai T, Nakata M, Tatsuta K, Kinoshita M. J. Am. Chem. Soc. $1995 ; 117: 3717$.

28. The absolute stereochemistry of the C9 carbinol was not rigorously established as it is ultimately inconsequential vis-à-vis $\mathbf{3}$. We assigned the C9 configuration based on studies of stereoselective hydride reductions of ketones Dauben WG, Fonken GH, Noyce DS. J. Am. Chem. Soc. 1956; 78:2579.

29. Scheidt KA, Chen H, Follows BC, Chemler SR, Coffey DS, Roush WR. J. Org. Chem. 1998; 63:6436.

30. Corey EJ, Kim CU. J. Am. Chem. Soc. 1972; 94:7586. 


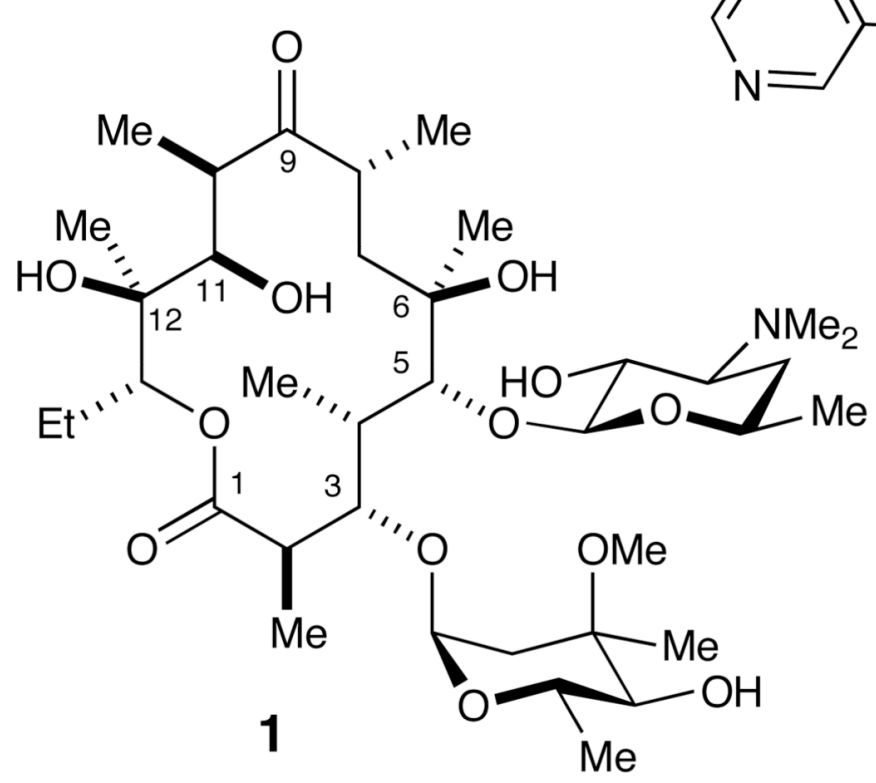

Erythromycin

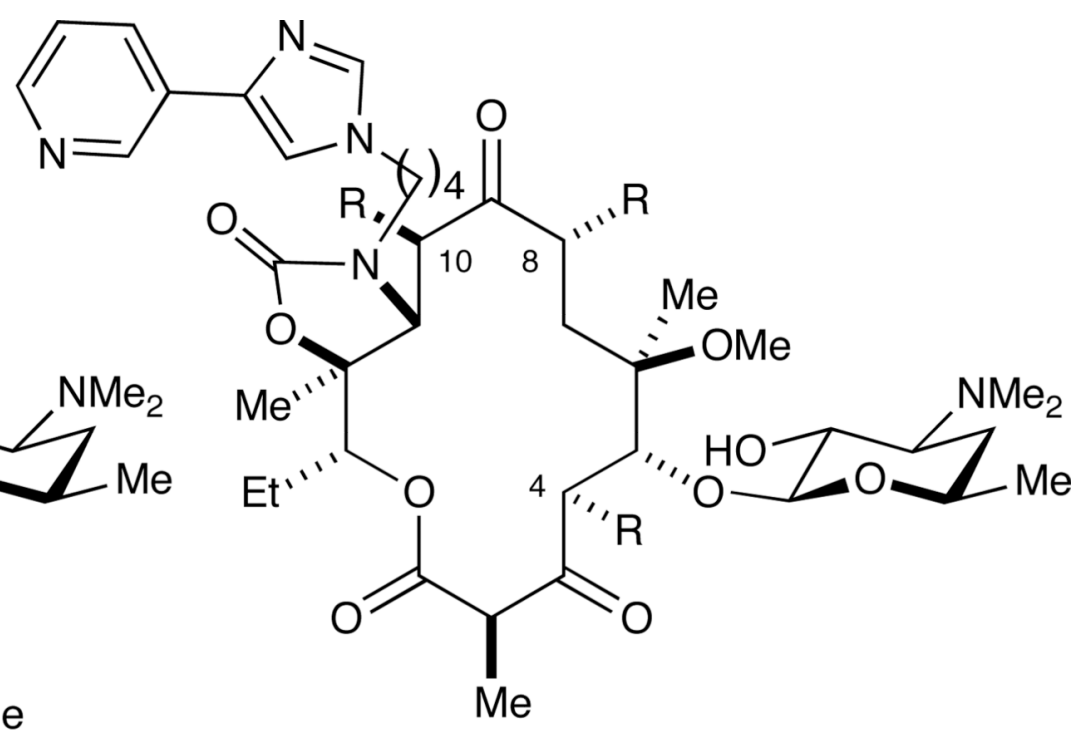

2: $\mathrm{R}=\mathrm{Me}=$ Telithromycin

3: $\mathrm{R}=\mathrm{H}=4,8,10$-Tridesmethyl Telithromycin

Figure 1.

Structures of erythromycin (1), telithromycin (2) and novel analogue (-)-4,8,10tridesmethyl telithromycin (3). 


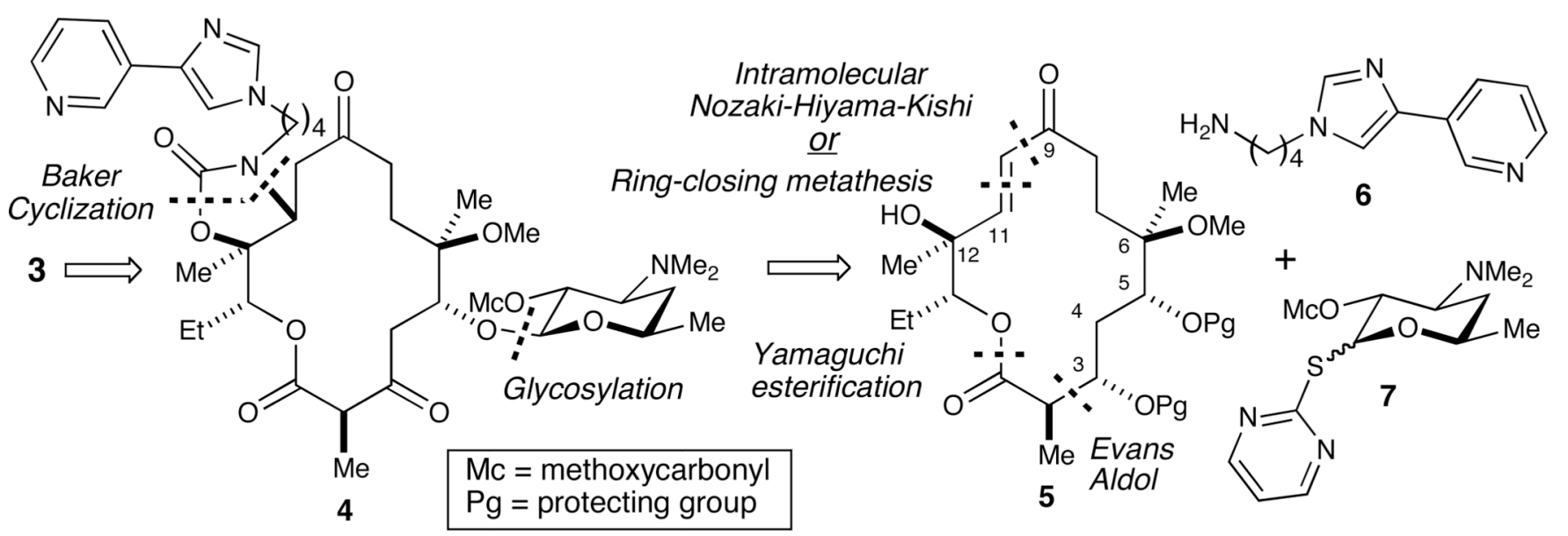<smiles>C=CPC=C[C@](C)(O)C(O)CC</smiles>

8: $R=1$

9: $\mathrm{R}=\mathrm{H}$

10

Scheme 1.

Retrosynthesis of (-)-4,8,10-tridesmethyl telithromycin (3). 
<smiles>CCC(O)C(C)=CC1C(C)C1[C@]1(C)OC1(C)CO</smiles>

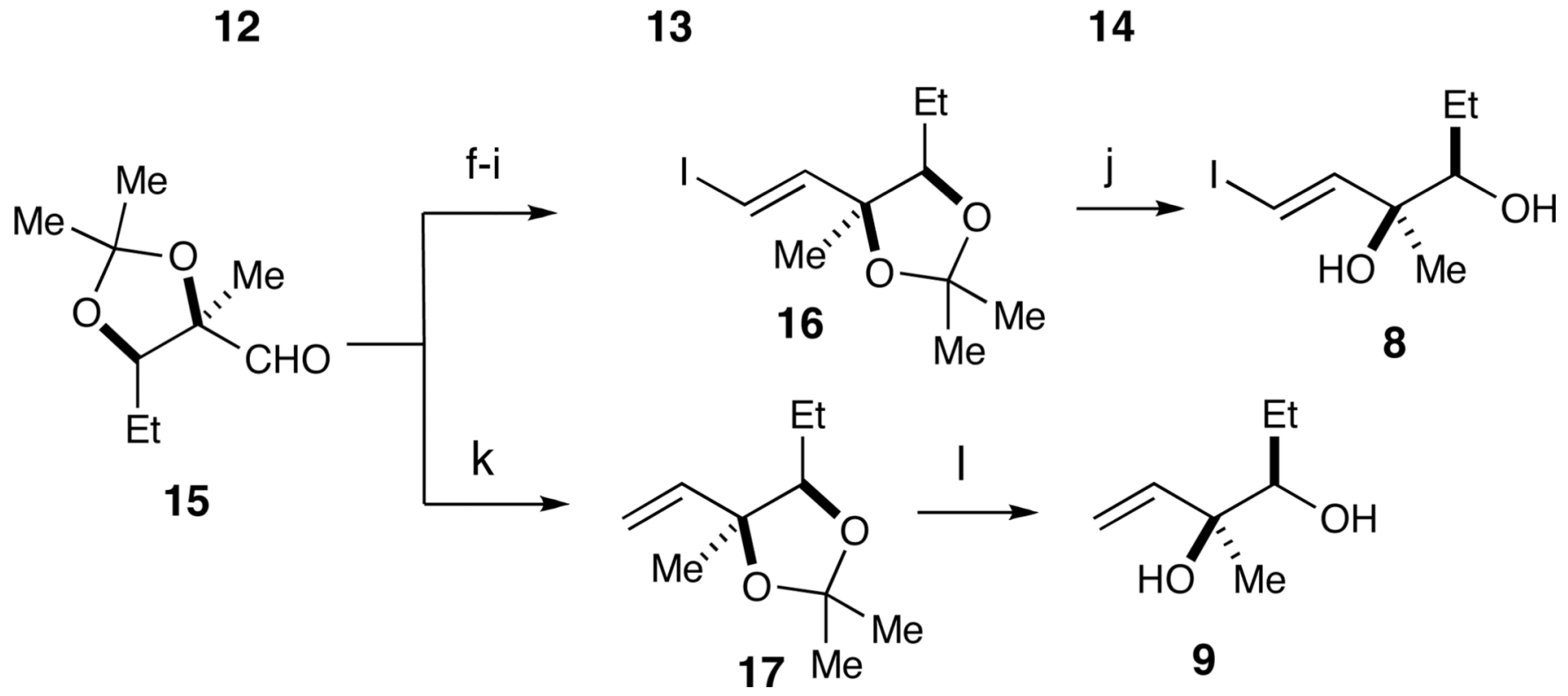

Scheme 2.

Synthesis of fragments 8 and 9 from aldehyde 15.a

a Reagents and conditions: (a) (-)-DIPT, Ti(O $i$-Pr) $)_{4}, t-\mathrm{BuOOH}, 32 \%$ (92\% ee); (b) $\mathrm{PivOH}$, $\mathrm{Ti}(\mathrm{O} i-\mathrm{Pr})_{4}$; (c) $\mathrm{Me}_{2} \mathrm{C}(\mathrm{OMe})_{2}$, PPTS; (d) MeLi, $59 \%$ over three steps; (e) $(\mathrm{COCl})_{2}$, DMSO, $\mathrm{Et}_{3} \mathrm{~N}$; (f) $\mathrm{CBr}_{4}, \mathrm{Ph}_{3} \mathrm{P}, \mathrm{CH}_{2} \mathrm{Cl}_{2}, 65 \%$ over two steps; (g) $n$-BuLi, THF, $90 \%$; (h) cat. AIBN, $\mathrm{Bu}_{3} \mathrm{SnH}, \mathrm{C}_{6} \mathrm{H}_{6}$; (i) $\mathrm{I}_{2}, \mathrm{CH}_{2} \mathrm{Cl}_{2}, 80 \%$ over two steps; (j) $1 \mathrm{~N} \mathrm{HCl}$ (aq.), $72 \%$; (k) $\mathrm{Ph}_{3} \mathrm{P}=\mathrm{CH}_{2}$; (l) $1 \mathrm{~N} \mathrm{HCl}$ (aq.), $53 \%$ over three steps from 14. 


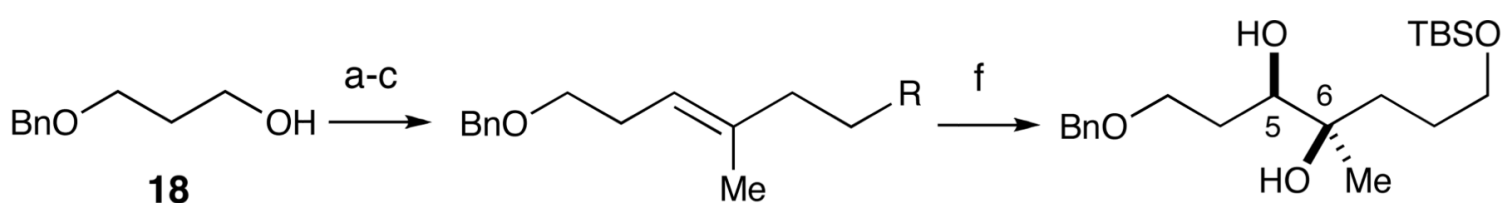

18

d-e $\square: \mathrm{R}=\mathrm{CO}_{2} \mathrm{Me}$
19: $\mathrm{R}=\mathrm{CH}_{2} \mathrm{OTBS}$

20

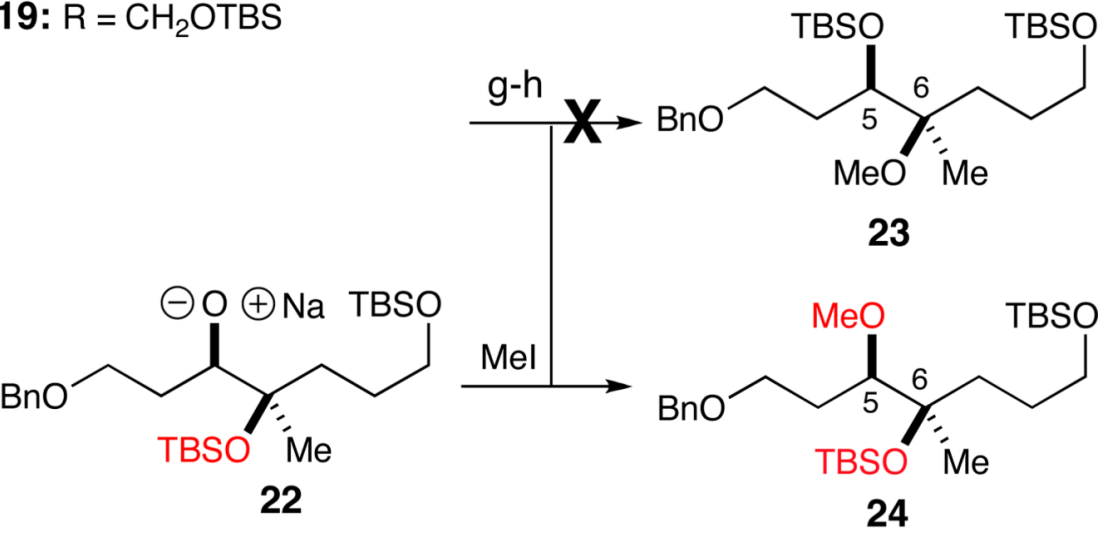

Scheme 3.

Unexpected synthesis of regioisomeric fragment 24.a

${ }^{a}$ Reagents and conditions: (a) $\left(\mathrm{COCl}_{2}\right.$, $\mathrm{DMSO}_{2} \mathrm{Et}_{3} \mathrm{~N}$; (b) 2-propenyl MgBr, THF; (c)

$(\mathrm{MeO})_{3} \mathrm{CCH}_{3}, \mathrm{EtCO}_{2} \mathrm{H}, 48 \%$ over three steps; (d) $\mathrm{LiAlH}_{4}, \mathrm{Et}_{2} \mathrm{O}$; (e) TBSCl, imidazole, $78 \%$ over two steps; (f) AD mix- $\beta, 91 \%$ (er>20:1); (g) TBSOTf, 2,6-lutidine; (h) NaH, MeI, $70 \%$ over two steps. 

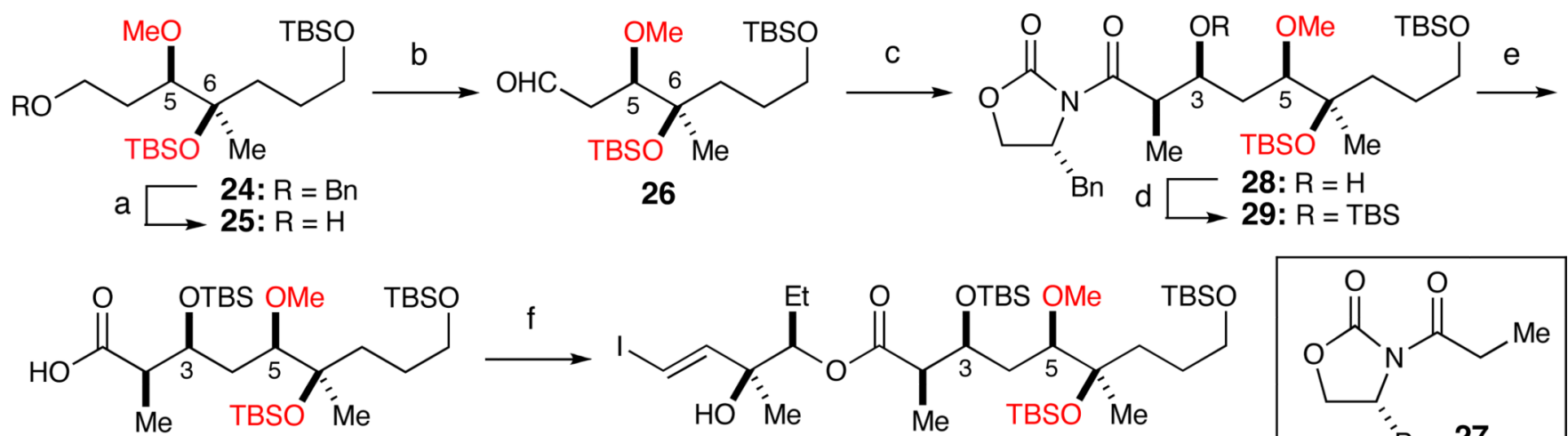

30

31

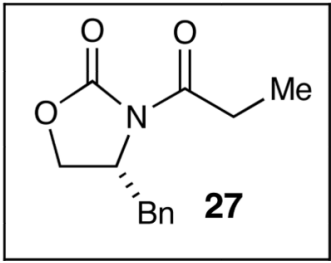

Scheme 4.

Elaboration of $\mathbf{2 4}$ into macrocyclization precursor 31.a

a Reagents and conditions: (a) $\mathrm{H}_{2}, \mathrm{Pd} / \mathrm{C}, 80 \%$; (b) $(\mathrm{COCl})_{2}$, DMSO, $\mathrm{Et}_{3} \mathrm{~N}$; (c) 27, $\mathrm{Bu}_{2} \mathrm{BOTf}$, $\mathrm{Et}_{3} \mathrm{~N}, 78 \%$ (dr>20:1) over two steps; (d) TBSOTf, 2,6-lutidine; (e) LiOOH, THF, $\mathrm{H}_{2} \mathrm{O}, 85 \%$ over two steps. (f) $\mathrm{Cl}_{3} \mathrm{PhCOCl}, \mathrm{Et}_{3} \mathrm{~N}, \mathrm{DMAP}, \mathbf{8}, 74 \%$. 


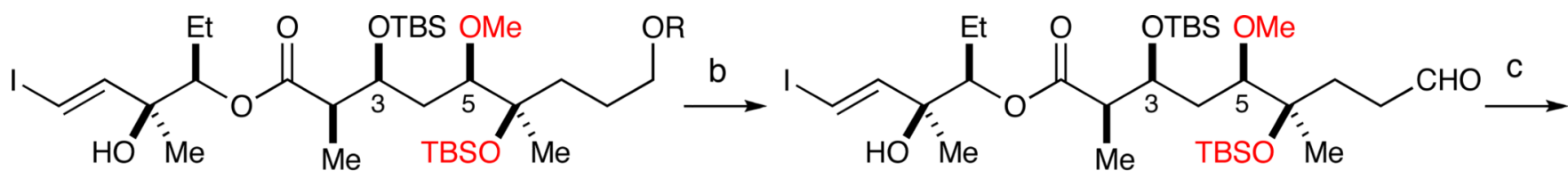

a 1 31: $R=$ TBS 32: $\mathrm{R}=\mathrm{H}$

33

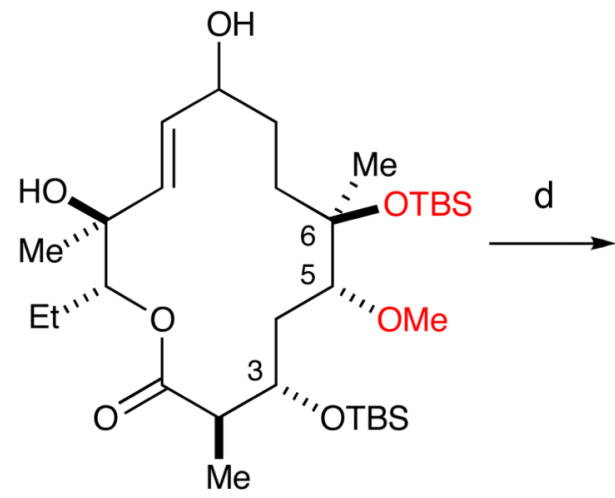

34

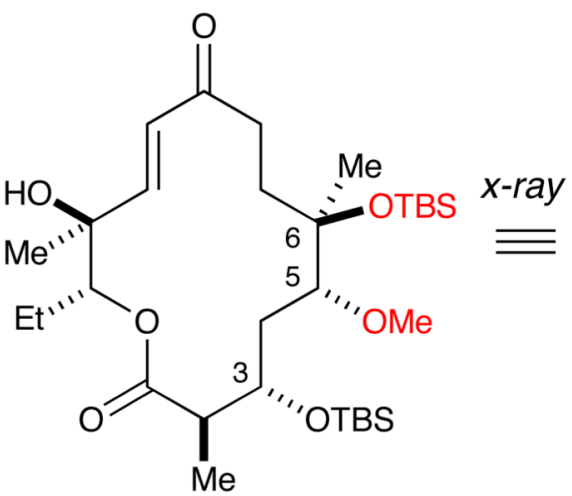

35

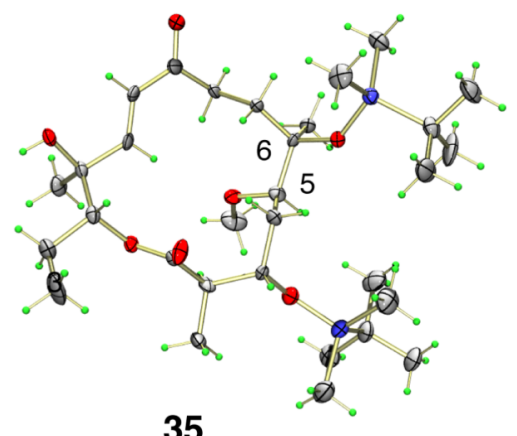

35

Scheme 5.

Macrocyclization of $\mathbf{3 3}$ and x-ray structure of macroketolactone $\mathbf{3 5}$. a

a Reagents and conditions: (a) CSA, $\mathrm{MeOH}, 85 \%$; (b) DMP, $\mathrm{NaHCO}_{3}, 80 \%$; (c) $\mathrm{CrCl}_{2}$, cat. $\mathrm{NiCl}_{2}$, DMSO, 50\%; (d) DMP, Pyridine, $82 \%$. 


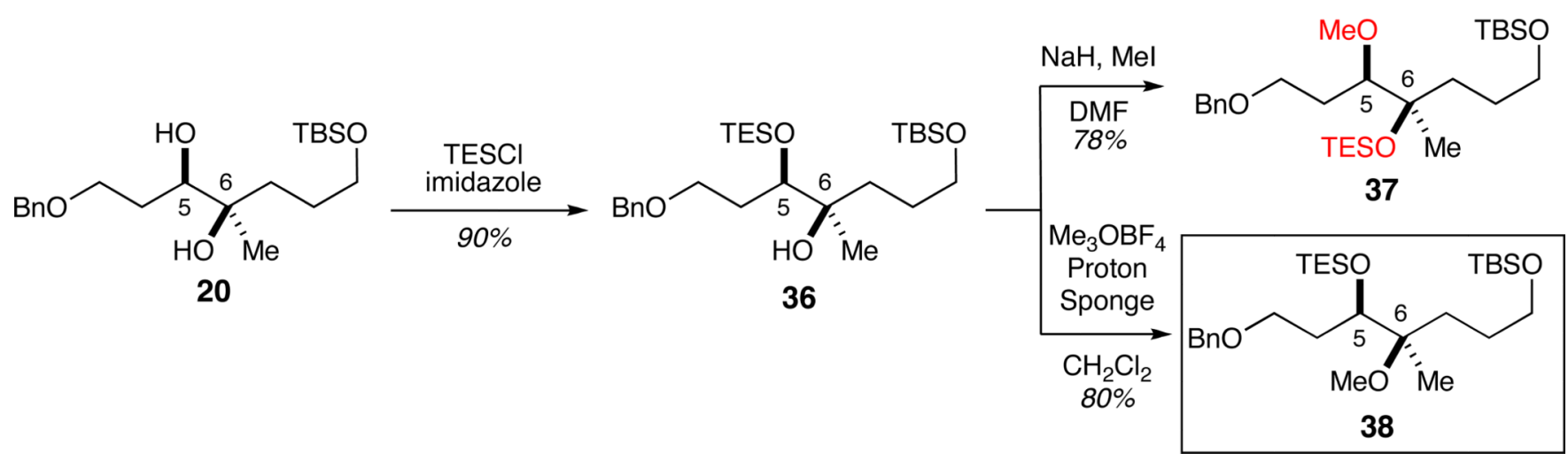

Scheme 6.

Synthesis of both regioisomeric fragments $\mathbf{3 7}$ and $\mathbf{3 8}$ (desired). 


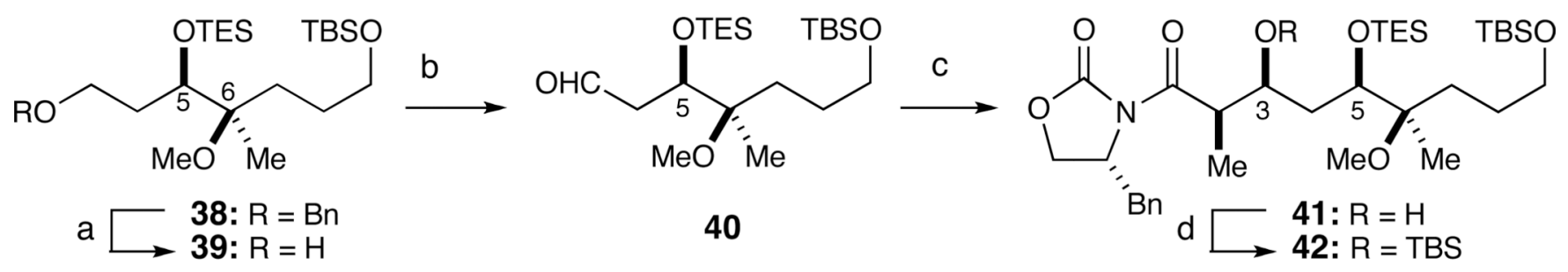

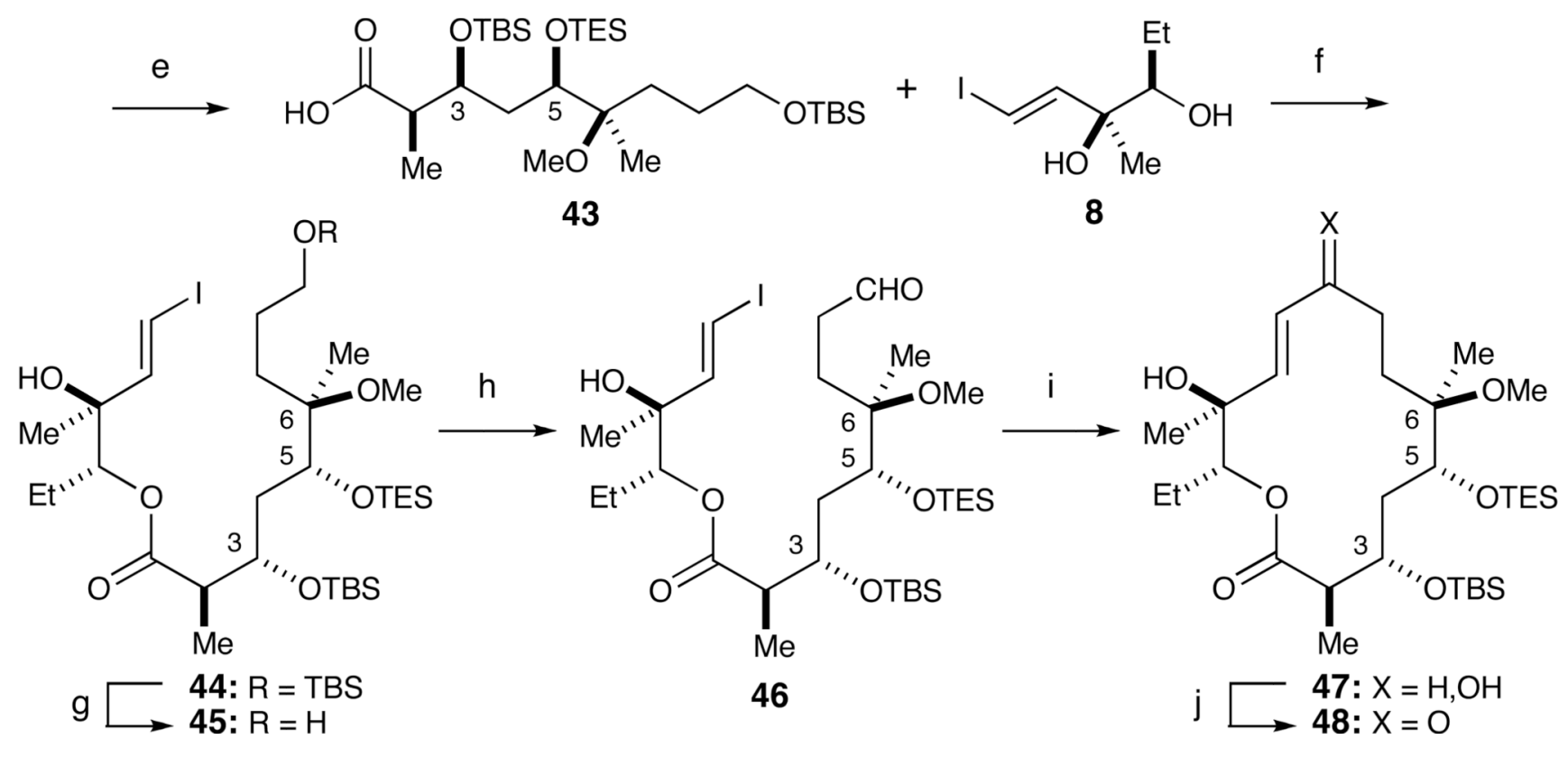

Scheme 7.

Intramolecular Nozaki-Hiyama-Kishi (NHK) route to macroketolactone 48.a

a Reagents and conditions: (a) $\mathrm{H}_{2}, \mathrm{Pd} / \mathrm{C}, 85 \%$; (b) $(\mathrm{COCl})_{2}$, DMSO, $\mathrm{Et}_{3} \mathrm{~N}$; (c) 27, $\mathrm{Bu}_{2} \mathrm{BOTf}$, $\mathrm{Et}_{3} \mathrm{~N}, \mathrm{dr}>20: 1,78 \%$ over 2 steps; (d) TBSOTf, 2,6-lutidine; (e) LiOOH, THF, $\mathrm{H}_{2} \mathrm{O}, 85 \%$ over two steps; (f) $\mathrm{Cl}_{3} \mathrm{PhCOCl}, \mathrm{Et}_{3} \mathrm{~N}$, DMAP, 75\%; (g) TBAF, AcOH, 60\%; (h) DMP, $\mathrm{NaHCO}_{3}, 78 \%$; (i) $\mathrm{CrCl}_{2}$, cat. $\mathrm{NiCl}_{2}$, DMSO, $50 \%$; (j) DMP, $80 \%$ 


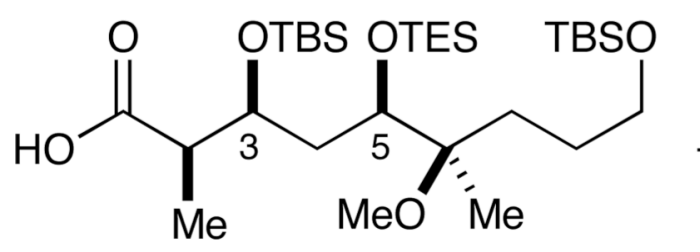

43

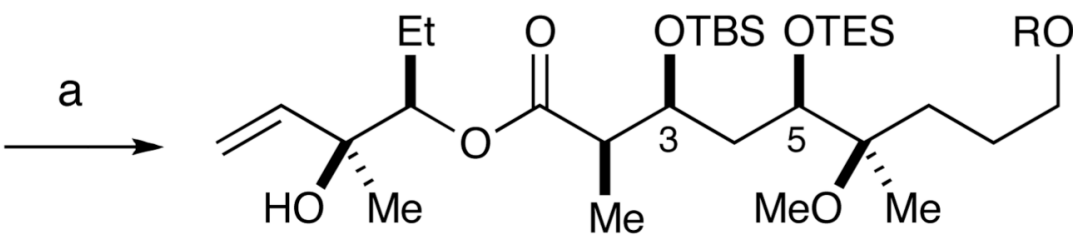

b

49: $R=T B S$ 50: $\mathrm{R}=\mathrm{H}$

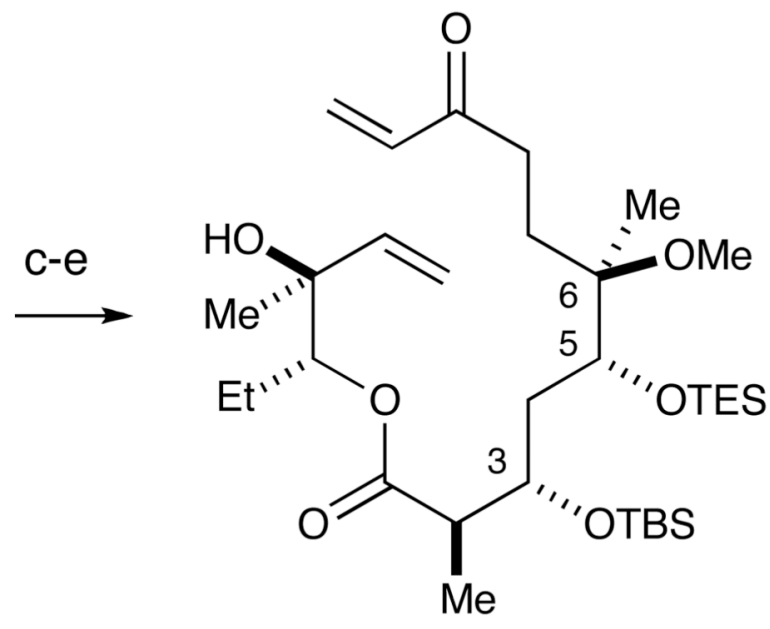

51

Scheme 8.

Alternate ring-closing metathesis (RCM) route to macroketolactone 48.a

a Reagents and conditions: (a) $\mathrm{Cl}_{3} \mathrm{PhCOCl}, \mathrm{Et}_{3} \mathrm{~N}$, DMAP, 9, 78\%; (b) TBAF, AcOH, 65\%;

(c) Dess-Martin Periodinane, $\mathrm{NaHCO}_{3}$; (d) Vinyl MgBr, THF; (e) Dess-Martin Periodinane, $\mathrm{CH}_{2} \mathrm{Cl}_{2}, 60 \%$ over three steps; (f) 20 mol\% Grubbs II cat., $60 \%$. 


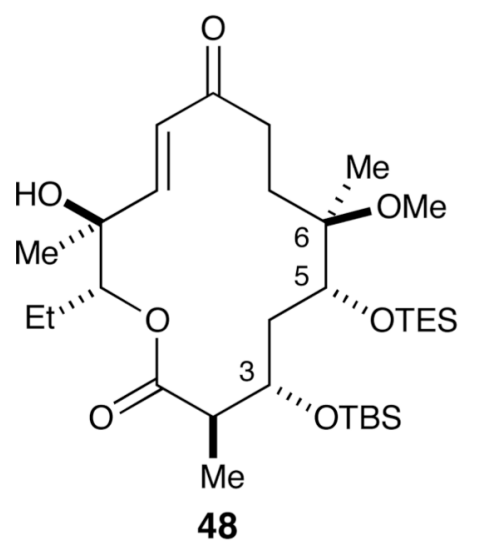
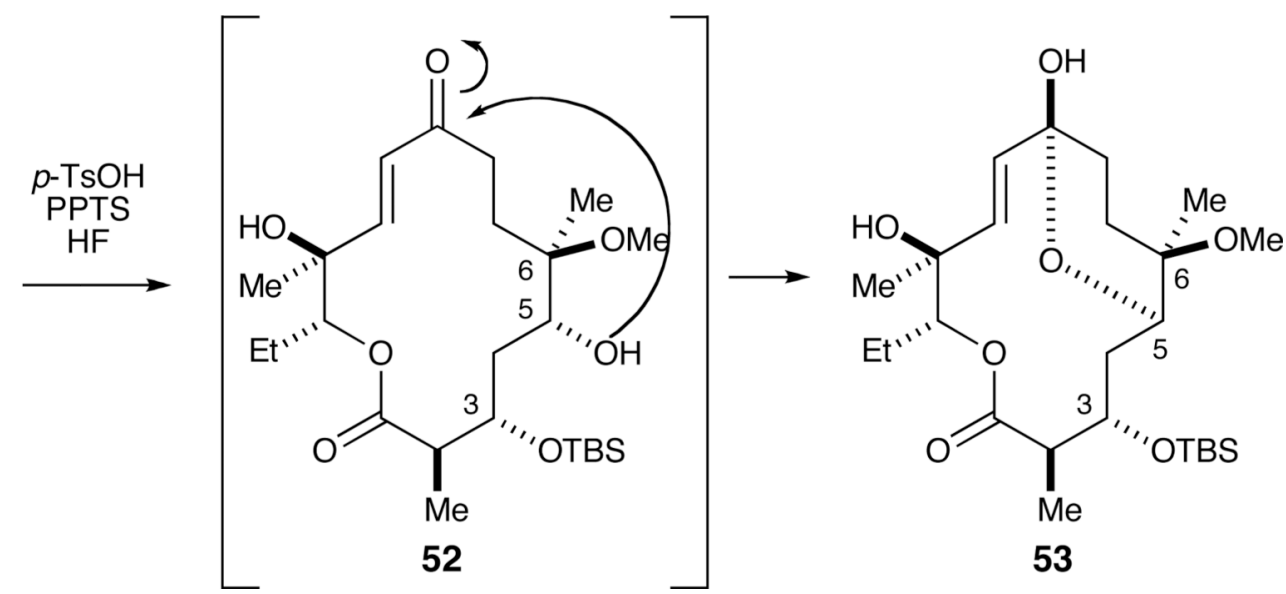

53

Scheme 9.

Selective removal of C5 TES group and attendant ketalization. 


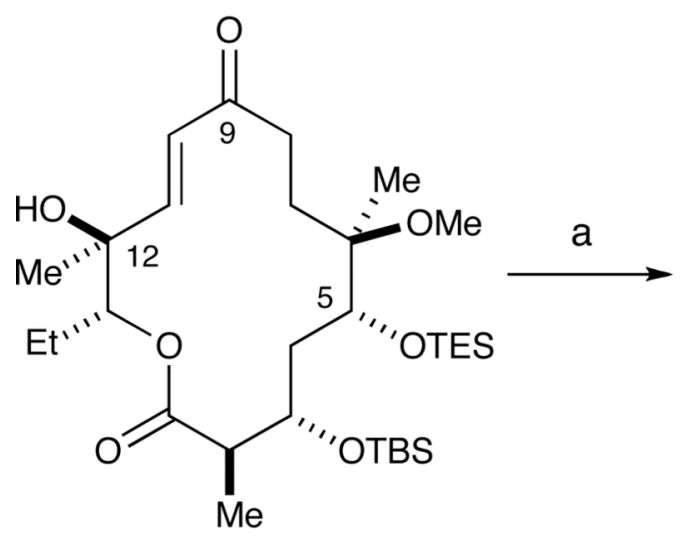

48

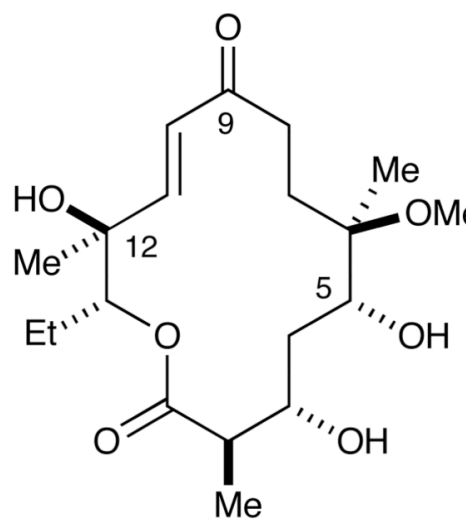

54
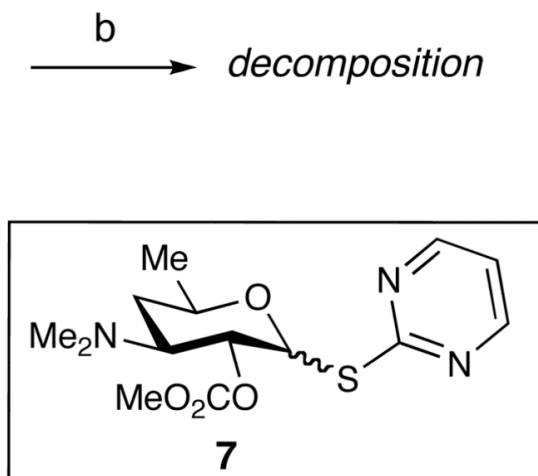

Scheme 10.

Unsuccessful regioselective glycosylation of diol $\mathbf{5 4}$ with donor 7.a

a Reagents and conditions: (a) TBAF, 4 A MS, THF, 70\%; (b) 7, AgOTf, DTBMP. 


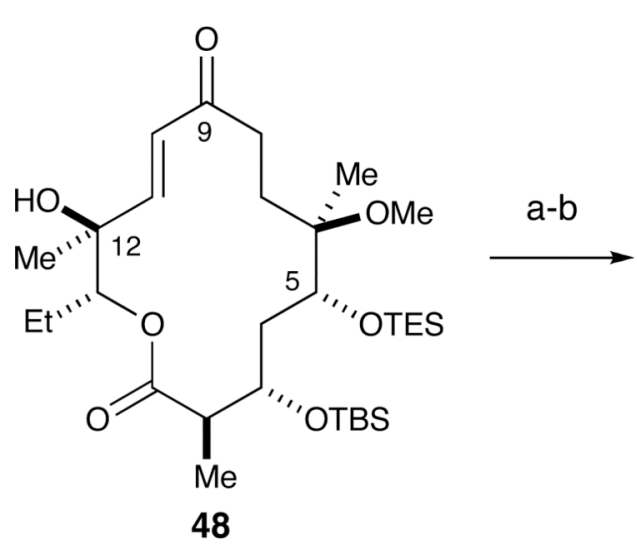

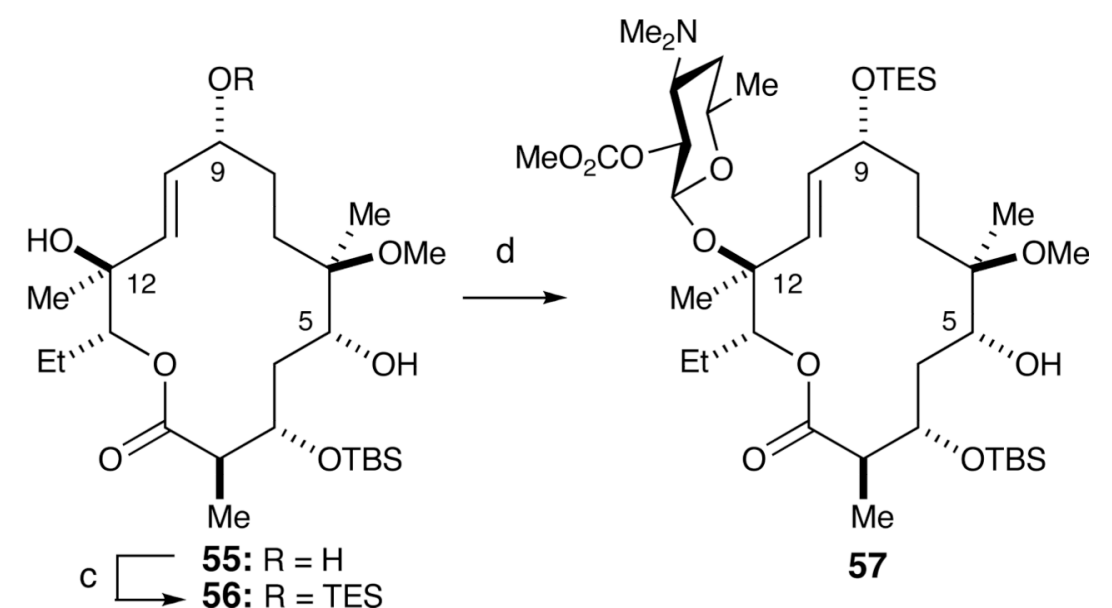

Scheme 11.

Unexpected glycosylation of tertiary C12 hydroxyl in the presence of secondary C5 hydroxyl.a

a Reagents and conditions: (a) $\mathrm{NaBH}_{4}, \mathrm{CeCl}_{3} \cdot 7 \mathrm{H}_{2} \mathrm{O}$, dr=7:1; (b) $p$-TsOH, $\mathrm{MeOH}, 75 \%$; (c)

TESCl, imidazole; (d) 7, AgOTf, DTBMP, $42 \%$ over two steps. 


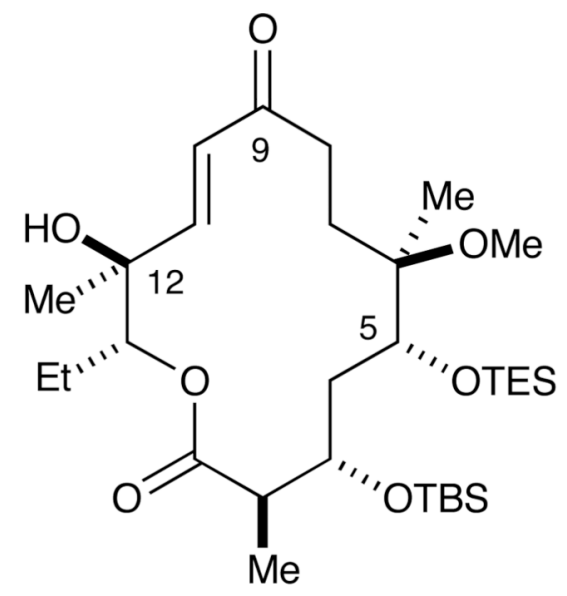

48

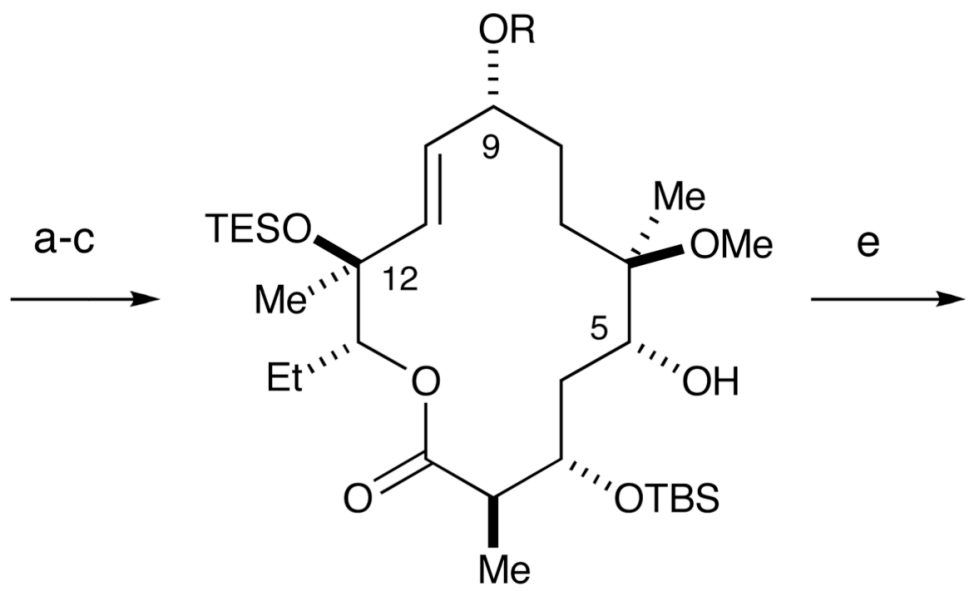

$\mathrm{d} \longrightarrow$ 58: $\mathrm{R}=\mathrm{H}$
$\mathrm{59}: \mathrm{R}=\mathrm{TES}$

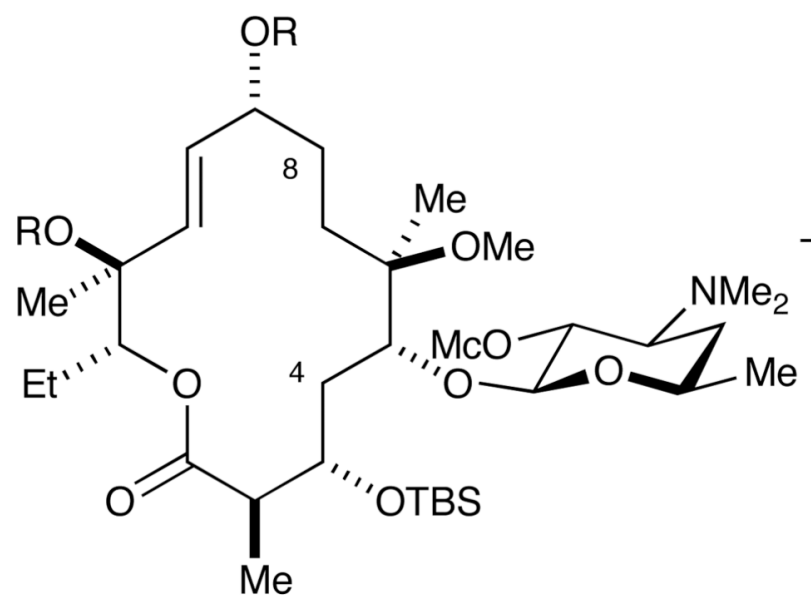

60: $R=$ TES

61: $\mathrm{R}=\mathrm{H}$

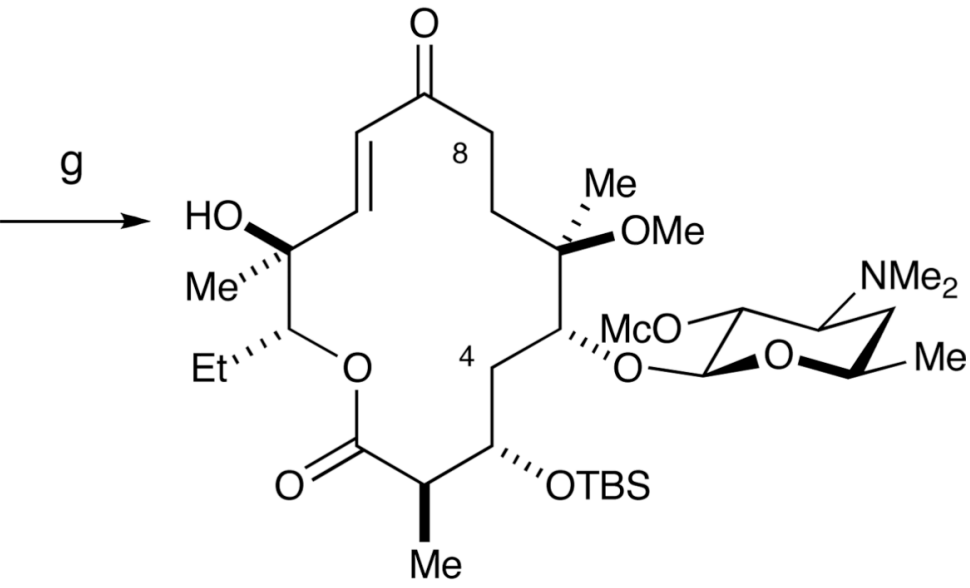

62

Scheme 12.

Synthesis of macroketolactone 62 .a

a Reagents and conditions: (a) $\mathrm{NaBH}_{4}, \mathrm{CeCl}_{3} \bullet 7 \mathrm{H}_{2} \mathrm{O}$, dr=7:1; (b) TESOTf, 2,6-lutidine; (c) p-TsOH, 52\% over three steps; (d) TESCl, imidazole; (e) 7, AgOTf, DTBMP, 50\% over two steps; (f) 1M TBAF, THF, 95\%; (g) DMP, $\mathrm{CH}_{2} \mathrm{Cl}_{2}, 88 \%$. 


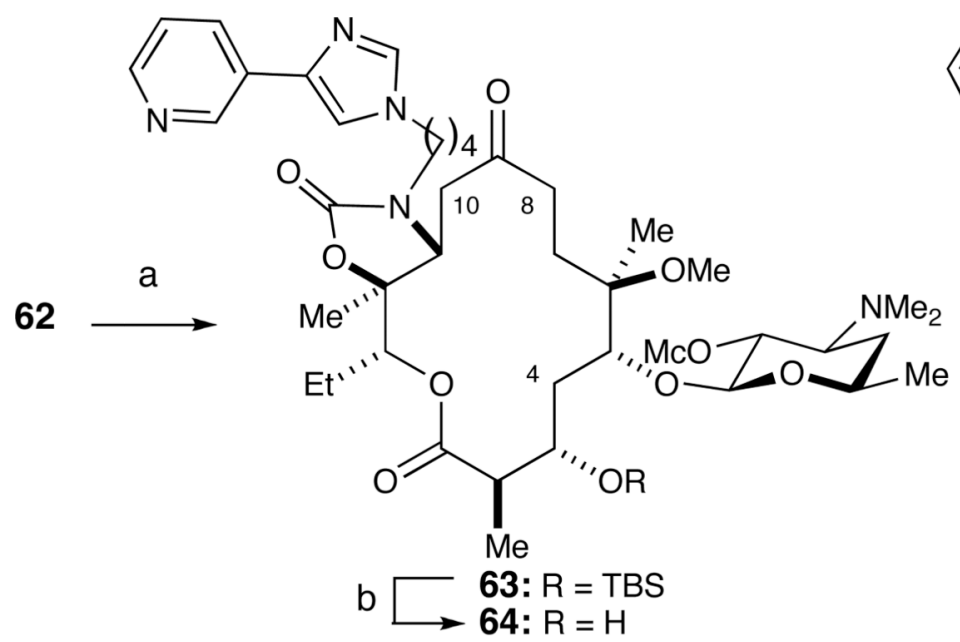

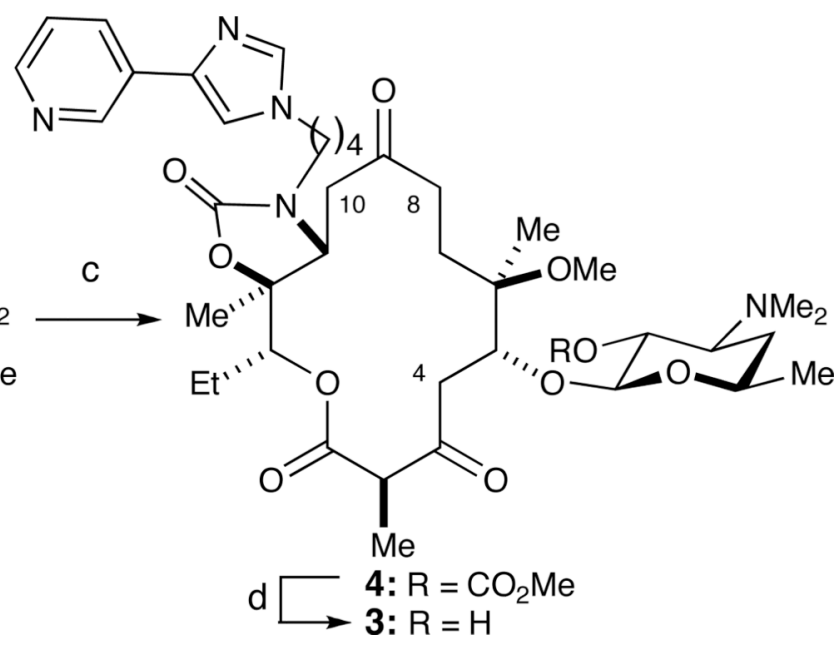

Scheme 13.

Endgame for (-)-4,8,10-tridesmethyl telithromycin (3).a

a Reagents and conditions: (a) NaH, CDI, THF/DMF then 6, 35\%; (b) TASF, DMF/ $\mathrm{H}_{2} \mathrm{O}$, $70 \%$; (c) NCS, DMS, $\mathrm{Et}_{3} \mathrm{~N}$; (d) $\mathrm{MeOH}, 45 \%$ over two steps. 